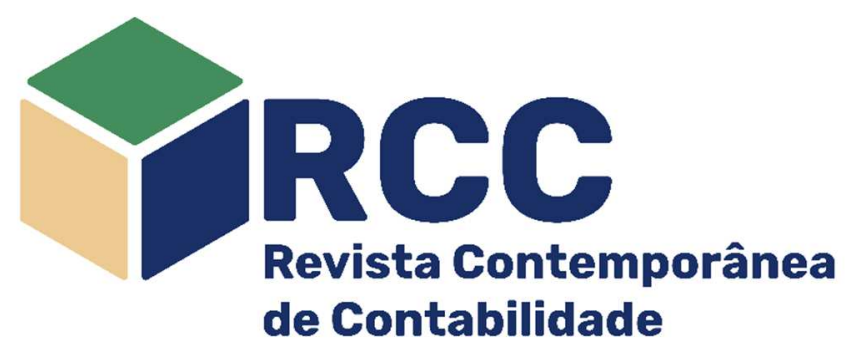

\title{
PIB brasileiro como carteira de mercado eficiente no modelo CAPM
}

\author{
Brazilian GDP as an efficient proxy for the return of market portfolios in the CAPM \\ PIB brasileño como cartera de mercado eficiente en el modelo CAPM
}

\author{
Victor Fontes Teixeira \\ Mestre em Ciências Contábeis e Finanças (UFES), \\ Vitória/ES, Brasil \\ victor fontes@ucl.br \\ https://orcid.org/0000-0002-2599-0552
}

Alfredo Sarlo Neto

Doutor em Controladoria e Contabilidade (USP) Professor Adjunto do Programa de Pós-Graduação em Ciências Contábeis (PPGCon) e da Graduação em Ciências Contábeis (UFES), Vitória/ES, Brasil supersarloneto@gmail.com https://orcid.org/0000-0002-6722-7192

Donizete Reina*

Doutorando em Ciências Contábeis (UFU) Professor do Departamento de Ciências Contábeis (UFES), Vitória/ES, Brasil dreina2@hotmail.com https://orcid.org/0000-0001-6217-2324

Endereço do contato principal para correspondência* Avenida Fernando Ferrari, 514, Campus Goiabeiras, CEP: 29075-010, Vitória/ES, Brasil

\section{Resumo}

No mercado financeiro, nota-se a existência de períodos em que há divergência entre os dados macroeconômicos (PIB, desemprego) e os dados do mercado acionário, principalmente os índices de ações. Questionando se o Ibovespa, retratam fidedignamente o cenário econômico nacional. O objetivo desta pesquisa foi testar a eficiência no sentido 'média-variância', de carteiras inspiradas na composição do PIB, como proxies para a carteira de mercado no modelo CAPM. Comparando-as com a eficiência do índice Bovespa para o mesmo objetivo. Para isto foi utilizada a análise de regressão multivariada em uma amostra de 148 empresas, num período de 10 anos, 2009 a 2018. Os resultados mostraram que nenhuma das carteiras apontadas, tanto quanto o índice Bovespa, são eficientes como representante do mercado brasileiro segundo o CAPM. No entanto, apesar de não cumprir as condições de eficiência estipuladas, o lbovespa se apresentou como a medida mais indicada para a carteira de mercado.

Palavras-chave: Carteira de mercado eficiente; PIB; CAPM

\begin{abstract}
In the financial market, there are often periods of divergence between macroeconomic data (GDP, unemployment) and stock market performance, especially as reflected by stock indexes, which often do not faithfully portray the national economic scenario. The objective of this study was to test the efficiency, in the "mean-variance" sense, of portfolios producing returns that track GDP as proxies for the market portfolio in the CAPM. We compared them with the efficiency of the main Brazilian stock market index, the lbovespa, for this purpose. To measure the efficiency, multivariate regression analysis was used in a sample of 148 firms, over a period of 10 years, 2009 to 2018. The results showed that none of the portfolios mentioned, along with the Ibovespa, were representative of the Brazilian market according to the CAPM. However, despite not meeting the stipulated efficiency conditions, the lbovespa was the most suitable measure of the market portfolio.
\end{abstract}

Keywords: Efficient Market Portfolio; GDP; CAPM 


\section{Resumen}

En el mercado financiero, a menudo hay períodos de divergencia entre los datos macroeconómicos (PIB, desempleo) y el desempeño del mercado de valores, especialmente como se refleja en los índices bursátiles, que a menudo no reflejan fielmente el escenario económico nacional. El objetivo de este estudio fue probar la eficiencia, en el sentido de "varianza media", de carteras que producen retornos que rastrean el PIB como sustitutos de la cartera de mercado en el CAPM. Los comparamos con la eficiencia del principal índice bursátil brasileño, el lbovespa, para este propósito. Para medir la eficiencia, se utilizó un análisis de regresión multivariante en una muestra de 148 empresas, en un período de 10 años, de 2009 a 2018. Los resultados mostraron que ninguna de las carteras mencionadas, junto con el lbovespa, eran representativas del mercado brasileño según al CAPM. Sin embargo, a pesar de no cumplir con las condiciones de eficiencia estipuladas, el lbovespa fue la medida más adecuada del portafolio de mercado.

Palabras clave: Cartera de mercado eficiente; PIB; CAPM

\section{Introdução}

No ano de 2019, o mercado acionário brasileiro encerrava a temporada alcançando sua máxima histórica, com o índice Bovespa atingindo 117.802 pontos. Tal fato poderia ser visto como sinal de um mercado interno aquecido e crescendo a passos largos. No entanto, dados macroeconômicos mostravam um cenário diferente. O principal indicador econômico, o PIB (produto interno bruto), que mede a produção nacional, registrava dados decrescentes desde 2014, como pode ser visto na Figura 1.

Apesar da retomada do PIB em 2017, enquanto o lbovespa rompia sua máxima anterior de 85.365 pontos, o PIB voltava a ter uma leve queda, não acompanhando o índice.

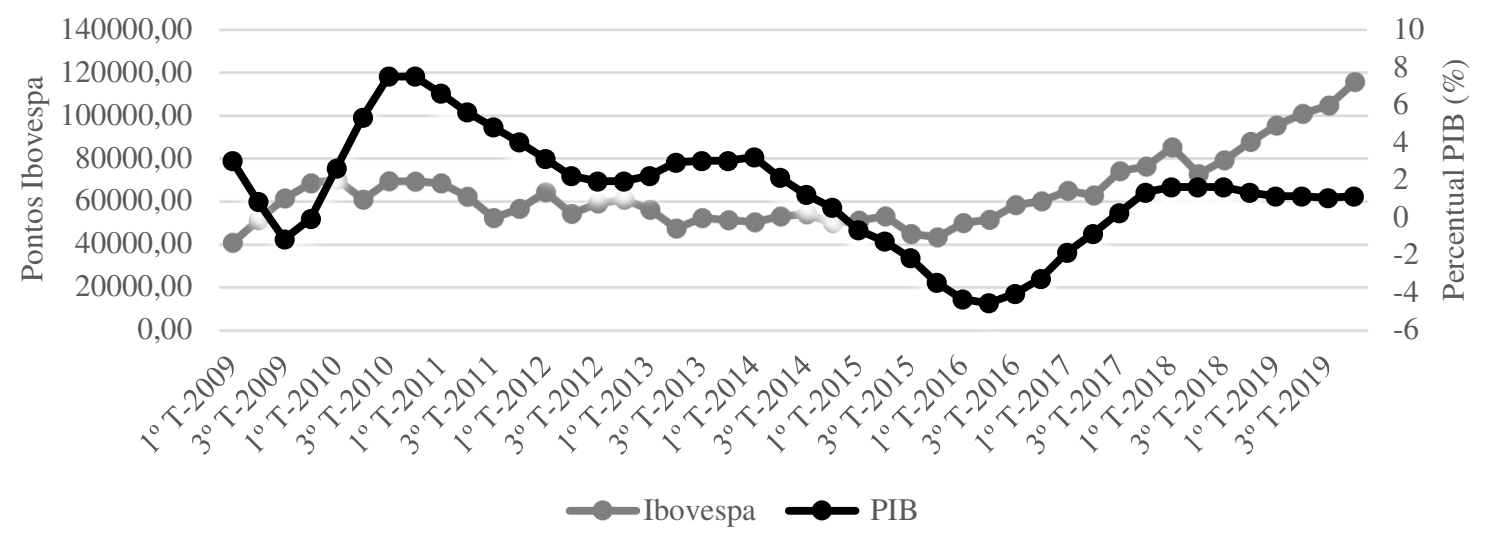

Figura 1: Ibovespa em comparação ao PIB

Fonte: Comdinheiro e Ipeadata

Autores como Fama (1981, p. 545), Kaul (1987, p. 254) e Barro (1990, p.130) já elucidaram a respeito da relação entre as variáveis macroeconômicas e os índices do mercado acionário. Indicando que as variações dos retornos do mercado poderiam predizer as variações das variáveis econômicas, como por exemplo, os níveis de investimento. Tendo em vista que o mercado acionário é um forte instrumento de captação de renda por parte das empresas. Logo, um aumento na captação de renda nas empresas, causaria um aumento no nível de investimento, por conseguinte, infringiria um aumento no padrão de produção industrial, levando consigo o produto interno de uma região.

O caminho inverso também é verdadeiro. Um aumento no PIB ampliaria os lucros das empresas, consequentemente elevando o preço das ações, impulsionando o índice Bovespa. Sobre a causalidade entre estas duas variáveis, diversos pesquisadores como, Nunes e Silva (2005), Silva e Coronel (2012), Bernardelli e Bernardelli (2016), Ribeiro, Leite e Justo (2016), Machado et al. (2018), Bernardelli e Castro (2020) encontraram uma causalidade significativa entre PIB e lbovespa. Ainda que alguns autores observaram essa causalidade em sentidos opostos (positiva ou negativa) em determinados períodos. Tal qual Pereira, Araújo e lquiapaza (2020) relata forte cointegração entre as variáveis, com alto poder de previsão do PIB sobre o lbovespa.

Os mesmo resultados e características foram experimentadas anteriormente por estudiosos do exterior, assim como, Fama (1990, p. 1107), Schewert (1989, p. 1256), Asprem (1989, p. 607), Chiang e Doong (1999) e Pilinkus (2009, p. 889). Em contrapartida, essa relação entre as duas variáveis não são unanimidade na comunidade científica. Nunes, Costa Jr. e Seabra (2003), Nunes, Costa Jr. e Meure (2005), Groppo (2004, p. 75), Silva Jr., Menezes e Fernandes (2011), Monteiro et al. (2013), Carvalho e Sekunda (2020) não mostram uma relação de causalidade significativa entre lbovespa e PIB. Não tendo o mercado de ações como um bom previsor do nível de produção interna, e vice-versa. Os mesmos resultados foram 
identificados por Kwon e Shin (1999), Omran (2003, p. 372), Dufour e Tessier (2006), Gan, Yong e Zhang (2006).

Silva Jr., Menezes e Fernandes (2011) salientam que em economias emergentes o comportamento de causalidade difere das economias de grandes potencias. Observando que as variáveis do mercado acionário possuem uma maior relação com produtividade. Contrapondo as suposições de que o mercado acionário antecipe as alterações nos fluxos de caixa futuro das empresas, consequentemente, os níveis futuros de atividade econômica.

Outro ponto a ser analisado dentro da problemática apresentada é a composição do lbovespa. 0 índice é uma carteira teórica formada por 76 ações. Quando analisada no horizonte temporal entre 2009 e 2018. Apenas 21 empresas se revezaram entre as 10 maiores participações. Deste grupo pode-se dizer que oito empresas (Bradesco, ItaúUnibanco, Petrobrás, Vale, $[\mathrm{B}]^{3}$, Itaúsa. Banco do Brasil e Ambev) estiveram em pelo menos metade das ocorrências. Três estiveram em todos os pregões (Bradesco, ItaúUnibanco, Petrobrás). O mesmo poderia ser dito sobre a Vale. No entanto, devido a tragédia de Mariana no final de 2015, a empresa sofreu uma enorme queda, ficando fora das 10 ações mais negociadas. Do conjunto de oito empresas, é importante destacar os casos de Petrobras, Vale e ItaúUnibanco, que já chegaram a representar $22,784 \%, 17,431 \%$ e $11,616 \%$ do Ibovespa, respectivamente. Além disso, outras empresas só fizeram parte dos 10 tickers mais negociados em casos específicos, impulsionados por fatos relevantes.

A Figura 2, mostra a variação da participação do grupo dos 10 tickers mais negociados do índice. Tendo seu mínimo em 40,769\% e máxima em 61,901\% do lbovespa, no período entre 2009 e 2018, representando uma média de $51,7068 \%$ de atuação no índice.

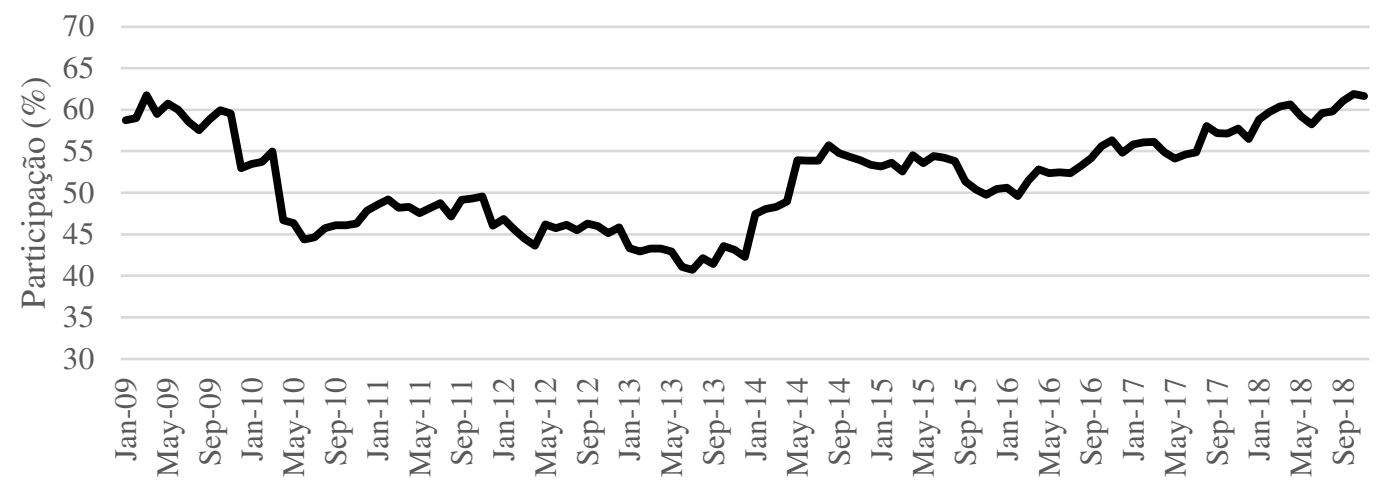

Figura 2: Soma dos pesos dos 10 tickers mais participativos do lbovespa

Fonte: Dados da pesquisa

Diante do exposto, buscando compreender a incerteza sobre o relacionamento entre Produto Interno Bruto e o índice Bovespa, esta pesquisa é direcionada pelo seguinte questionamento: $O$ índice Bovespa pode ser adotado como uma proxy de mercado eficiente para as companhias pertencentes ao contexto brasileiro? Para responder a tal questionamento, o objetivo desta pesquisa foi testar a eficiência de carteiras do mercado de capitais, adotando a composição do PIB como proxies para a carteira de mercado no modelo CAPM, comparando-as com a eficiência do índice Bovespa.

A importância desse estudo se dá em função de investigar a lacuna de alta concentração do lbovespa, que por sua vez é o indicador do desempenho médio das cotações dos ativos de maior negociabilidade e representatividade da $[\mathrm{B}]^{3}$, adotando a composição dos fechamentos mensais entre os 10 tickers com maior peso na formação do índice Para isto, esta pesquisa se utilizou do modelo de precificação de ativos CAPM (Capital Asset Pricing Model), que apresenta a proposição básica de conter uma carteira de ativos que represente de modo eficiente o mercado ao qual está inserido (conhecida por 'carteira de mercado eficiente'), cuja finalidade é demonstrar o retorno de todos os ativos de mercado, maximizando os retornos esperados.

Por fim, esta pesquisa propõe três carteiras de mercado, baseando suas formações nos setores de composição do PIB e, divididas em: (i) negociabilidade (PIB-negociabilidade); (ii) presença (PIB-presença); e, (iii) igualmente ponderada (PIB-número), com objetivo de testar a eficiência ex-ante, confrontando-as com a eficiência do lbovespa. Desta forma, o estudo se diferencia da pesquisa de Araujo, Farjado e Di Tavani (2006), dado que, os mesmos utilizaram o Produto Interno Bruto como o dividendo pago por uma carteira hipotética, mas sem apresentar uma carteira de mercado eficiente para o modelo CAPM.

\section{Referencial teórico}

Desde 1952, a Moderna Teoria de Carteiras de Markowitz tem sido utilizada como um pilar para os modelos de precificação de ativos. O principal e mais difundido modelo de precificação de ativos foi o CAPM (Capital Asset Pricing Model). Tendo sido desenvolvido e aperfeiçoado, por Sharpe (1964, p. 425) e Lintner (1965, p. 587), o modelo é empregue até os dias atuais. 
Para a estimação do CAPM é necessária a estimação de uma carteira de mercado, que abranja todos os ativos do mercado que está inserido. No entanto, Roll (1977, p. 130) afirma que "[...] a teoria não pode ser testada, a menos que a composição exata do verdadeiro portfólio de mercado seja conhecida e usada nos testes. Isso implica que a teoria não pode ser testada, a menos que todos os ativos individuais sejam incluídos na amostra". O autor ainda complementa elencando dois problemas quanto a eficiência da carteira de mercado. Primeiro, de que a proxy pode ser eficiente em "média-variância", mesmo o verdadeiro portfólio de mercado não sendo. Segundo, as proxies mais razoáveis estarão altamente correlacionadas entre si e com o mercado real, independentemente de serem ou não eficientes em "média-variância".

Em contrapartida, Guermat (2014, p. 27) mostra que o modelo CAPM é realmente aplicável. O autor se baseia em Kandel e Stambaugh (1995) e Kan, Robotti e Shanken (2013), que assumindo a premissa de inexistência de variáveis ocultas no modelo, busca a condição de máximo $R^{2}$ no CAPM, através da estimação por Mínimos Quadrados Ordinários (MQO) e Mínimos Quadrados Generalizados (MQG). Condição que só ocorre quando a carteira de mercado é eficiente e quando não há variáveis omitidas.

Pereira e Laurini (2020), buscaram uma abordagem diferente para o teste de portifólio eficiente do CAPM. Comparando a aplicabilidade dos estimadores do Método dos Momentos Generalizado (GMM) e o Método de Verossimilhança Empírica Generalizada (GEL). Os pesquisadores identificaram uma mudança de resultados quanto aos modelos aplicados e quanto a característica da amostra ser finita ou não. As amostras infinitas se aproximaram mais de ser eficientes, já as finitas tiveram suas eficiências "super-rejeitadas". Assim, entende-se que a aplicabilidade do modelo CAPM está sujeita as decisões de premissas do usuário e o mercado onde está inserido. Aos participantes do mercado financeiro, uma solução alternativa para contornar a limitação do alcance da carteira de mercado, é utilizar o índice de maior representatividade do mercado, no Brasil, índice Bovespa.

No contexto brasileiro, alguns pesquisadores buscaram comprovar a eficiência do lbovespa como carteira de mercado eficiente. Volpe (2010, p. 52) comparou o Ibovespa, o IBrX (índice Brasil), o FGV-100 (índice da Fundação Getúlio Vargas), uma carteira ponderada a valor de mercado e uma igualmente ponderada, ambas propostas pelo mesmo. No período entre 1996 e 2009, todos os índices obtiveram resultados muito próximos, não se mostrando eficientes. Hagler e Brito (2007), testaram as eficiências dos mesmos índices, através da versão Sharpe-Lintner e Black do CAPM no período de 1989 até 2003. Onde nenhum índice foi eficiente. Silva e Motta (2002) aplicando a versão Black entre 1986 e 2001, mostraram que o lbovespa não foi eficiente no longo prazo. Sendo eficiente em janelas mais curtas. Já Araújo, Fajardo e Di Tavani (2006) tomaram como base a metodologia de Hou (2002, p. 3), testando uma carteira hipotética que pagava o PIB como dividendo e, comparando-a com o lbovespa. Os modelos escolhidos foram a versão Sharpe-Lintner e a versão Black do CAPM, entre 1991 e 2002. Concluindo que tal carteira não demonstrou ser eficiente.

\subsection{Produto interno bruto (PIB)}

Como definido pelo IBGE (Instituto Brasileiro de Geografia e Estatística), o PIB é uma medida de crescimento econômico, que representa a soma de toda riqueza produzida por uma região (cidade, estado, país) em um determinado espaço de tempo. Esta pesquisa utiliza o PIB pela ótica da oferta. Este método baseia-se na determinação do valor acrescentado por cada unidade produtiva, calculado através da diferença entre o valor das vendas e o valor das compras que foi necessário efetuar para conseguir realizar a produção.

Tabela 1:

\begin{tabular}{|c|c|c|c|c|c|c|c|c|c|c|c|}
\hline \multicolumn{2}{|c|}{ ANO } & 2009 & 2010 & 2011 & 2012 & 2013 & 2014 & 2015 & 2016 & 2017 & 2018 \\
\hline \multicolumn{2}{|c|}{ AGROPECUÁRIA } & 149,213 & 159,932 & 190,024 & 200,695 & 240,29 & 249,975 & 258,967 & 306,655 & 303,751 & 297,77 \\
\hline \multirow{4}{*}{ 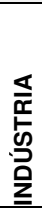 } & Extrativa & 62,705 & 109,965 & 162,567 & 186,191 & 189,434 & 184,797 & 110,773 & 55,559 & 94,398 & 174,155 \\
\hline & Transfor. & 435,277 & 494,352 & 515,704 & 514,021 & 558,733 & 597,376 & 630,813 & 675,816 & 690,731 & 659,664 \\
\hline & Siup & 76,616 & 92,914 & 99,219 & 100,233 & 92,818 & 93,975 & 123,183 & 143,698 & 148,519 & 165,437 \\
\hline & Constru. & 154,624 & 206,927 & 233,544 & 265,237 & 290,641 & 306,946 & 296,018 & 275,134 & 269,193 & 259,944 \\
\hline \multirow{7}{*}{ 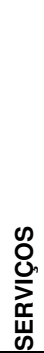 } & Comércio & 361,914 & 416,229 & 478,242 & 548,339 & 614,087 & 676,562 & 685,708 & 699,15 & 715,714 & 769,365 \\
\hline & Transporte & 109,403 & 141,66 & 165,557 & 183,063 & 203,421 & 227,757 & 226,5 & 235,851 & 250,823 & 256,085 \\
\hline & Informação & 122,173 & 126,542 & 137,006 & 148,451 & 157,509 & 168,61 & 176,004 & 178,982 & 183,944 & 187,025 \\
\hline & Financeiros & 187,593 & 224,561 & 239,426 & 260,312 & 272,571 & 318,68 & 365,276 & 425,476 & 425,238 & 405,416 \\
\hline & Imobiliários & 247,217 & 274,42 & 311,38 & 358,947 & 419,202 & 463,781 & 498,884 & 526,995 & 551,972 & 577,205 \\
\hline & Outros & 455,85 & 517,493 & 589,733 & 676,669 & 768,867 & 867,467 & 897,888 & 949,262 & $1,020,721$ & $1,063,107$ \\
\hline & Adm. Púb. & 487,179 & 537,845 & 598,059 & 652,101 & 746,187 & 816,808 & 885,587 & 945,121 & 985,873 & $1,017,943$ \\
\hline
\end{tabular}


Observando a Tabela 1, nota-se que do grupo de 21 empresas que compõem até $60 \%$ do Ibovespa, a oito mais relevantes (Bradesco, Itaú Unibanco, Petrobrás, Vale, $[\mathrm{B}]^{3}$, Itaúsa, Banco do Brasil e Ambev) fazem parte de apenas três dos 12 setores do PIB, que são os grupos de extração mineral, transformação e instituições financeiras, onde juntos, estes setores somam em torno de $26 \%$ de toda riqueza criada no país. Logo, aproximadamente $74 \%$ da economia brasileira não está sendo bem representada no modelo CAPM quando se utiliza o lbovespa como proxy de mercado. Sendo constatado que os setores de Agropecuária e Serviços são afetados devido a concentrado do índice Bovespa.

\subsection{Modelo CAPM conforme versão Sharpe-Lintner}

Neste estudo, foi selecionada a versão Sharpe-Lintner do modelo CAPM, por esta incluir o princípio de que a tomada e concessão de empréstimos à taxa livre de risco. A economia brasileira se aproxima de ter ativos com retorno estipulado pela taxa livre de risco, que são as Letras Financeiras do Tesouro (LFT's), atreladas a taxa Selic. Nesse sentido, assume-se a Selic como ativo livre de risco, uma vez que são esperados excessos de retorno acima da mesma, com a aplicação em ativos mais arriscados. Além disso, julga-se que seu risco está aposto a capacidade de pagamento do país, denominando-o como "risco zero".

Fama e French (2007) destacam que, os testes do CAPM se baseiam em três implicações da relação entre retorno esperado e beta de mercado implícitas no modelo. Primeira, os retornos esperados de todos os ativos apresentam relação linear com seus betas e nenhuma outra variável tem poder explicativo marginal. Segunda, o prêmio do beta é positivo, o que significa que o retorno esperado da carteira de mercado supera o de ativos cujos retornos não estejam correlacionados com o retorno do mercado. Terceira, na versão Sharpe-Lintner do modelo, os ativos não correlacionados com o mercado têm retornos esperados iguais à taxa de juros livre de risco, e o prêmio do beta é o retorno esperado do mercado menos a taxa livre de risco. Assim, assumindo a existência de $N$ ativos de risco, têm-se a representação de acordo com a Equação 1.

$$
\mathrm{E}\left(\mathrm{R}_{\mathrm{i}}\right)=\mathrm{E}\left(\mathrm{R}_{\mathrm{f}}\right)+\left[\mathrm{E}\left(\mathrm{R}_{\mathrm{m}}\right)-\mathrm{E}\left(\mathrm{R}_{\mathrm{f}}\right)\right] \beta_{\mathrm{im}} \quad \forall \mathrm{i}=1, \ldots, \mathrm{N}
$$

Em que: $\mathrm{E}\left(\mathrm{R}_{\mathrm{i}}\right)$ = retorno esperado do ativo $\mathrm{i} ; \mathrm{E}\left(\mathrm{R}_{\mathrm{f}}\right)$ = retorno esperado do ativo livre de risco; $\mathrm{E}\left(\mathrm{R}_{\mathrm{m}}\right)=$ retorno esperado do mercado; $\left[E\left(R_{m}\right)-E\left(R_{f}\right)\right] \beta_{i m}=$ prêmio de risco; e, $\beta_{\text {im }}=$ beta de mercado do ativo i.

Adotando-se a perspectiva de Campbell, Lo e MacKinlay (1997) assume-se a existência de $\mathrm{N}$ ativos arriscados de retorno $\mathrm{R}_{\mathrm{it}}$, tal que $\mathrm{i}=1, \ldots, \mathrm{N}$ e um ativo sem risco de retorno $\mathrm{R}_{\mathrm{ft}}$ para cada período. Assim, reescrevendo a Equação 1 de forma matricial, tem-se como resultado a Equação 2. Com $Z_{i}=\left[E\left(R_{i}\right)-E\left(R_{f}\right)\right]$ e $\mathrm{Z}_{\mathrm{m}}=\left[\mathrm{E}\left(\mathrm{R}_{\mathrm{m}}\right)-\mathrm{E}\left(\mathrm{R}_{\mathrm{f}}\right)\right]$.

$$
\mathrm{Z}_{\mathrm{t}}=\alpha+\mathrm{Z}_{\mathrm{mt}} \beta+\epsilon_{\mathrm{t}}
$$

Em que: $\mathrm{Z}_{\mathrm{t}}=$ é um vetor $(\mathrm{Nx} 1)$ de excessos de retornos dos ativos i em relação ao ativo livre de risco no período $\mathrm{t} ; \mathrm{Z}_{\mathrm{mt}}=$ é o excesso de retorno da carteira $\mathrm{m}$ em relação ao ativo livre de risco no período $\mathrm{t} ; \beta=$ é o vetor de betas $(\mathrm{Nx} 1)$; e, $\epsilon_{\mathrm{t}}=$ é o vetor (Nx1) do termo de erro para os ativos i no período t, independentes e identicamente distribuídos ao longo do tempo.

Se uma dada carteira m é eficiente na versão Sharpe-Lintner, então a condição pode ser representada conforme a Equação 3.

$$
\mathrm{E}\left(\mathrm{Z}_{\mathrm{t}}\right)=\beta \cdot \mathrm{E}\left(\mathrm{Z}_{\mathrm{m}}\right)
$$

Satisfazer tal condição, implica na restrição dos interceptos como nulos, sem significância estatística para o modelo, conforme a hipótese nula como mostra a Equação 4.

$$
\mathrm{H}_{0}: \alpha_{1}=\alpha_{2}=\alpha_{3}=\alpha_{4}=\cdots=\alpha_{\mathrm{n}}=0 \quad \text { e } \quad \mathrm{H}_{1} \text { : qualquer } \alpha_{\mathrm{i}} \neq 0
$$

A hipótese $\mathrm{H}_{0}$ é violada se, e somente se, alguma combinação linear dos interceptos $\alpha$ for diferente de zero, ou seja, se e somente se alguma carteira dos $\mathrm{N}$ ativos arriscados tiver um intercepto diferente de zero quando se faz a regressão de seus excessos de retorno nos excessos de retorno da carteira m.

Para a mensuração dos estimadores irrestritos, Campbell, Lo e MacKinlay (1997) utilizam quatro estatísticas para a realização dos testes de eficiência, nomeadas pelos mesmos autores de estatísticas $\mathrm{J}_{0}, \mathrm{~J}_{1}$, $\mathrm{J}_{2}$ e $\mathrm{J}_{3}$. Assim, pode-se formular um teste de Wald para a hipótese nula (4), contra a hipótese alternativa $\mathrm{H}_{\mathrm{a}}: \alpha \neq 0$. A estatística teste $\mathrm{J}_{0}$ para o teste de Wald é definida conforme as Equações 5, 6 e 7.

$$
\begin{gathered}
\mathrm{J}_{0}=\widehat{\alpha}^{\prime}[\operatorname{Var}(\widehat{\alpha})]^{-1} \widehat{\alpha} \\
\mathrm{J}_{0}=\mathrm{T}\left[1+\frac{\hat{\mu}_{\mathrm{m}}{ }^{2}}{{\widehat{\sigma_{\mathrm{m}}}}^{2}}\right] \widehat{\alpha}^{\prime} \widehat{\Sigma}^{-1} \widehat{\alpha} \sim \chi_{\mathrm{N}}^{2} \\
\mathrm{~J}_{1}=\frac{(\mathrm{T}-\mathrm{N}-1)}{\mathrm{N}}\left[1+\frac{\hat{\mu}_{\mathrm{m}}{ }^{2}}{{\widehat{\sigma_{\mathrm{m}}}}^{2}}\right] \widehat{\alpha}^{\prime} \widehat{\Sigma}^{-1} \widehat{\alpha} \sim \mathrm{F}(\mathrm{N}, \mathrm{T}-\mathrm{N}-1)
\end{gathered}
$$

Em que: $\mathrm{J}_{0}$ e $\mathrm{J}_{1}$ referem-se ao modelo irrestrito. Nesse sentido, quando é inserida a restrição $\alpha=0$ os novos estimadores a e $\beta$ resultam nas Equações 8 e 9.

$$
\widehat{\beta}^{*}=\frac{\sum_{\mathrm{t}=1}^{\mathrm{T}} \mathrm{Z}_{\mathrm{t}} \mathrm{Z}_{\mathrm{mt}}}{\sum_{\mathrm{t}=1}^{\mathrm{T}} \mathrm{Z}_{\mathrm{mt}}^{2}} \sim \mathrm{N}\left(\beta, \frac{1}{\mathrm{~T}}\left[\frac{1}{\hat{\mu}_{\mathrm{m}}{ }^{2}+\widehat{\sigma}_{\mathrm{m}}{ }^{2}}\right] \Sigma\right)
$$




$$
\widehat{\Sigma}^{*}=\frac{1}{\mathrm{~T}} \sum_{\mathrm{t}-1}^{\mathrm{T}}\left(\mathrm{Z}_{\mathrm{t}}-\hat{\beta}^{*} \mathrm{Z}_{\mathrm{mt}}\right)\left(\mathrm{Z}_{\mathrm{t}}-\hat{\beta}^{*} \mathrm{Z}_{\mathrm{mt}}\right)^{\prime} \therefore \mathrm{T} \widehat{\Sigma} \sim \mathrm{W}_{\mathrm{N}}(\mathrm{T}-1, \Sigma)
$$

Após a identificação dos estimadores irrestritos e restritos, foi realizado o teste de razão de verossimilhança. O teste é baseado no resultado assintótico de que, sob a hipótese nula, -2 vezes o logaritmo da razão de verossimilhança tem distribuição qui-quadrada com graus de liberdade iguais ao número de restrições sob $\mathrm{H}_{0}$, conforme Equação 10. Logo, é possível testar $\mathrm{H}_{0}$ usando a Equação 11.

$$
\mathrm{J}_{2}=\mathrm{T} \log \left(\left[\frac{\widehat{\mathrm{\sigma}}_{\mathrm{m}}{ }^{2}}{\hat{\mu}_{\mathrm{m}}{ }^{2}+\widehat{\sigma}_{\mathrm{m}}{ }^{2}}\right] \widehat{\alpha}^{\prime} \widehat{\Sigma}^{-1} \widehat{\alpha}+1\right) \sim \chi_{\mathrm{N}}^{2}
$$

Com o ajuste para amostras finitas sugerido por Jobson e Korkie (1982) tem-se a Equação 12.

$$
\mathrm{J}_{3}=\left(\mathrm{T}-\frac{\mathrm{N}}{2}-2\right)\left[\log \left|\widehat{\Sigma}^{*}\right|-\log |\widehat{\Sigma}|\right] \sim \chi_{\mathrm{N}}^{2}
$$

É importante ressaltar que os testes $\mathrm{J}_{1}$ e $\mathrm{J}_{3}$ são semelhantes aos testes $\mathrm{J}_{0} \mathrm{e} \mathrm{J}_{2}$. No entanto, $\mathrm{J}_{1}$ e $\mathrm{J}_{3}$ se ajustam para amostram finitas. Assim, após realizados os testes estatísticos $\mathrm{J}_{0}, \mathrm{~J}_{1}, \mathrm{~J}_{2}$ e $\mathrm{J}_{3}$, ainda foi realizado o teste da eficiência da carteira de mercado em separado. A eficiência em "média-variância" pode ser testada via teste t, através da razão de Sharpe conforme Equação 13.

$$
\mathrm{SR}_{\mathrm{m}}=\frac{\mu_{\mathrm{m}}-\mathrm{R}_{\mathrm{f}}}{\sigma_{\mathrm{m}}} \therefore \mathrm{H}_{0}: \mathrm{Z}_{\mathrm{m}}=0
$$

De acordo com Campbell, Lo e MacKinlay (1997), o excesso de retorno esperado por risco unitário é útil para fornecer uma base para a interpretação econômica dos testes do CAPM. A proporção Sharpe mede essa quantidade. Para qualquer ativo ou portfólio $a$, o índice Sharpe é definido como o excesso de retorno médio dividido pelo desvio padrão do retorno.

Testar a eficiência da variação média de um determinado portfólio é equivalente a testar se o índice Sharpe desse portfólio, representa o máximo do conjunto de índices Sharpe de todos os portfólios possíveis. Desta forma, as hipóteses $\mathrm{H}_{1}$ e $\mathrm{H}_{2}$ são: $\mathrm{H}_{1}$ : Uma carteira hipotética de mercado baseada na composição do $\mathrm{PIB}$, formada por empresas de cada setor, explica por si só o retorno de uma carteira de ativos; e, $\mathrm{H}_{2}$ : Uma carteira hipotética de mercado baseada na composição do PIB, formada por empresas de cada setor, é eficiente em "média-variância".

\section{Metodologia da pesquisa}

\subsection{Procedimentos de pesquisa e características da amostra}

Todas as cotações mensais de empresas foram extraídas das bases da $[\mathrm{B}]^{3}$ e da Comdinheiro. Os primeiros preços de fechamento disponíveis foram selecionados com uma tolerância de cinco dias úteis. As informações das variáveis macroeconômicas foram retiradas do banco de dados do IBGE e do Bacen. Ademais, as empresas selecionadas como ativos foram selecionadas de forma aleatória resultando num total de 70 papéis, separadas em dez carteiras de acordo com o tamanho do beta de cada carteira.

Ao todo foram coletados dados de 148 empresas, totalizando 17.244 observações. Viu-se necessária a aceitação de empresas com até $15 \%$ de dados faltantes, para que nenhum setor ficasse sem empresa representante. O período analisado foi de 10 anos, entre janeiro de 2009 e dezembro de 2018, conforme Tabela 2, subdividido em quatro subperíodos de 30 meses, para avaliar a eficiência das carteiras no curto prazo. O período escolhido foi em razão da estabilidade econômica brasileira, onde encontra-se melhor estabilidade da inflação e equilíbrio monetário.

Tabela 2:

Períodos analisados

\begin{tabular}{lll}
\hline Período & Nomenclatura & T \\
\hline 01/2009-12/2018 & Período 0 & 120 \\
$\mathbf{0 1 / 2 0 0 9 - 0 6 / 2 0 1 1}$ & Período 1 & 30 \\
$\mathbf{0 7 / 2 0 1 1 - 1 2 / 2 0 1 3}$ & Período 2 & 30 \\
$\mathbf{0 1 / 2 0 1 4 - 0 6 / 2 0 1 6}$ & Período 3 & 30 \\
$\mathbf{0 7 / 2 0 1 6 - 1 2 / 2 0 1 8}$ & Período 4 & 30 \\
\hline
\end{tabular}

Fonte: Dados da pesquisa

Para cada ativo da amostra, o retorno composto foi calculado através do logaritmo neperiano. Esses são retornos contínuos e são representados pela Equação 14.

$$
\mathrm{R}_{\mathrm{it}}=\ln \left(\mathrm{P}_{\mathrm{it}} / \mathrm{P}_{\mathrm{it}-1}\right)
$$

Em que: $\mathrm{P}_{\mathrm{it}}=$ é o preço do ativo $i$ no mês $t ; \mathrm{e}, \mathrm{P}_{\mathrm{it}-1}=$ é o preço do ativo $i$ no mês $t-1$.

O retorno do ativo livre de risco estabelecido como parâmetro para a construção das séries de excessos de retorno foi a Selic overnight mensal, obtida junto ao Ipeadata e ao Bacen (série 4390). A série trimestral de composição do PIB a valor real, através da ótica da oferta, foi obtida junto ao IBGE, no Sistema 
de Contas Nacionais Trimestrais (SCNT). Assim, para selecionar as carteiras de ativos a presente pesquisa se baseou em Gibbons, Ross e Shanken (1989), que realizando os testes de eficiência para o CAPM zerobeta, dividiram os ativos em carteiras segundo três critérios: i) Dez carteiras em função do beta de cada ativo em relação ao índice que estava sendo testado; ii) 12 carteiras por setor industrial; e, iii) Dez carteiras em função do tamanho das firmas. No entanto, devido a menor dimensão do mercado brasileiro, possuindo uma quantidade menor de empresas.

As carteiras de ativos selecionadas nesse trabalho, foram determinadas apenas pelo tamanho de seus betas. Os betas foram calculados por meio da razão entre a covariância do ativo e a carteira de mercado com a variância da carteira de mercado. A carteira de mercado escolhida foi o lbovespa. As carteiras a serem testadas contra os portfólios propostos, também forma selecionadas conforme o tamanho de seus betas contra o lbovespa. Tal fato não deve influenciar nos testes de eficiência, uma vez que, qualquer carteira de ativos que for verificada junto as carteiras de mercado, precisa não rejeitar a hipótese de $\mathrm{H}_{0}: \alpha=0$.

\subsection{Formação das carteiras de mercado}

O peso de cada um dos 12 segmentos de mercado para a montagem das carteiras, foi estabelecido através da média aritmética da composição do PIB no período de análise. Este método foi escolhido devido as variáveis apresentarem baixa dispersão em torno das médias. Conforme pode visto na Tabela 3.

Tabela 3:

Estatística descritiva do produto interno bruto (PIB)

\begin{tabular}{l|lllllll}
\hline Setores & \multicolumn{1}{c}{$\bar{X}$} & \multicolumn{1}{c}{$\sigma$} & \multicolumn{1}{c}{$M$} & Min & Max & Assim. & Curt. \\
\hline Agropecuária & 44.144 & 0.2273 & 43.517 & 41.158 & 4.893 & 0.6629 & -0.498 \\
Ext. Mineral & 25.769 & 10.289 & 26.903 & 0.8865 & 38.671 & -0.2035 & -15.848 \\
Transformação & 110.563 & 10.997 & 106.076 & 96.617 & 130.595 & 0.7069 & -10.568 \\
Construção & 21.442 & 0.2703 & 22.666 & 16.262 & 24.231 & -0.8013 & -0.9427 \\
Siup & 48.814 & 0.6113 & 51.243 & 38.073 & 55.088 & -0.5001 & -14.762 \\
Indústria & 206.588 & 19.444 & 208.486 & 183.528 & 23.268 & -0.0007 & -1.793 \\
Comércio & 111.893 & 0.3271 & 112.121 & 107.114 & 117.073 & 0.044 & -15.759 \\
Transporte & 37.388 & 0.1763 & 37.803 & 32.824 & 39.411 & -15.701 & 16.834 \\
Informação & 30.345 & 0.2708 & 29.449 & 27.393 & 36.655 & 10.921 & 0.2118 \\
Financeiro & 58.219 & 0.5163 & 57.036 & 51.123 & 67.889 & 0.5183 & -1.049 \\
Imobiliário & 78.543 & 0.5539 & 7.944 & 7.062 & 8.454 & -0.2193 & -17.987 \\
Outros & 145.222 & 0.8519 & 146.981 & 133.174 & 155.744 & -0.1348 & -1.756 \\
Adm. Pública & 143.599 & 0.589 & 143.754 & 135.438 & 150.804 & -0.0656 & -1.854 \\
Serviços & 605.209 & 22.331 & 604.649 & 575.682 & 631.994 & -0.0696 & -18.476 \\
\hline Fonte: Dados da pesqus
\end{tabular}

Fonte: Dados da pesquisa

Os setores de Indústria e Serviços representam a soma da participação de seus subsetores. Logo não foram usados na formação dos pesos das ações por setor, apenas as participações dos subsetores foram utilizadas. Além do setor de Agropecuária que não possui subdivisão.

As 148 empresas foram alocadas entre os segmentos de forma manual. Pois os setores do PIB são diferentes dos setores da $[\mathrm{B}]^{3}$. Dessa forma, as empresas foram separadas de acordo com suas atividades fim, sua forma de geração de valor. O subsetor de administração pública foi retirado dos segmentos por não possuir empresas listadas na bolsa.

A separação das carteiras aconteceu de acordo com três características, negociabilidade ou volume negociado, presença em pregões, e igualmente ponderada, com o mesmo peso a todos os ativos. As carteiras foram então nomeadas de PIB-negociabilidade, PIB-presença e PIB-número.

\subsection{Formação da carteira PIB-negociabilidade}

Para a composição da primeira carteira, denominada PIB-negociabilidade, foram selecionadas 68 empresas dos segmentos presentes na composição do produto interno bruto, onde cada empresa teve seu peso percentual determinado pela divisão do número de empresas no setor pela porcentagem do mesmo na composição do PIB. Sendo assim, o retorno da carteira de mercado foi calculado de acordo com a Teoria Moderna de Carteiras de Markowitz (1952) conforme representado na Equação 15.

$$
\mathrm{R}_{\mathrm{m}}=\sum_{\mathrm{i}=1}^{\mathrm{N}} \mathrm{X}_{\text {setor }} \mathrm{R}_{\text {setor }}
$$


Em que: $\mathrm{R}_{\text {setor }}=$ retorno do setor; $\mathrm{X}_{\text {setor }}=$ peso do setor na carteira; $\mathrm{X}_{\mathrm{i}, \text { setor }}=$ peso da empresa dentro do seu setor de participação; $e, \mathrm{R}_{\mathrm{i}}=$ retorno da empresa.

Os critérios estabelecidos para a seleção das empresas de cada setor foram semelhantes as diretrizes de composição do índice bovespa, entretanto, não podem ser aplicadas com total rigor, pois a carteira apresenta um número elevado de empresas e setores que não figuram frequentemente os quadros de negociabilidade e volume transacionado. Foram selecionadas as empresas com maior negociabilidade, contendo pelo menos uma empresa em cada grupo conforme dispostas na Tabela 4.

\section{Tabela 4:}

Composição da carteira de mercado PIB-negociabilidade

\begin{tabular}{|c|c|c|c|}
\hline \multicolumn{2}{|c|}{ Classificação } & \begin{tabular}{|l|}
$\mathrm{n}-\mathrm{de}$ \\
ativos
\end{tabular} & Composição da carteira \\
\hline \multicolumn{2}{|c|}{ Agropecuária } & 4 & BRFS3 / JBSS3 / MRFG3 / BEEF3 \\
\hline \multirow{4}{*}{ 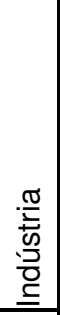 } & Ext. mineral & 5 & PETR4 / VALE3 / PETR3 / OGXP3 / MMXM3 \\
\hline & Transformação & 12 & $\begin{array}{l}\text { GGBR4 /ABEV3 / USIM5 / CSNA3 / GOAU4 / EMBR3 / CSAN3 / WEGE3 / } \\
\text { KLBN4 / RAPT4 / MYPK3 / MDIA3 }\end{array}$ \\
\hline & Construção & 4 & CYRE3 / MRVE3 / EVEN3 / EZTC3 \\
\hline & Siup & 12 & $\begin{array}{l}\text { CCRO3 / CMIG4 / VIVT4 / BRKM5/ SBSP3 / ENBR3 / EQTL3 / CESP6 / } \\
\text { CPFE3 / CPLE6 / LIGT3 / TRPL4 }\end{array}$ \\
\hline \multirow{5}{*}{ 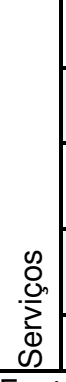 } & Comércio & 8 & LREN3 / LAME4 / PCAR4 / NATU3 / RENT3 / RADL3 / HGTX3 / BTOW3 \\
\hline & $\begin{array}{l}\text { Trans. arm. e } \\
\text { correio }\end{array}$ & 2 & GOLL4 / POMO4 \\
\hline & $\begin{array}{l}\text { Serviços de } \\
\text { informação } \\
\end{array}$ & 4 & CIEL3 / ESTC3 / TOTS3 / VLID3 \\
\hline & $\begin{array}{l}\text { Financeiras e } \\
\text { seguros }\end{array}$ & 8 & ITUB4 / BBDC4 / BBAS3 / ITSA4 / BBDC3 / BRSR6 / SULA11 / PSSA3 \\
\hline & Outros & 3 & BRAP4 / OIBR4 / ODPV3 \\
\hline
\end{tabular}

Fonte: Dados da pesquisa

\subsection{Formação da carteira PIB-presença}

A formação da segunda carteira proposta, nomeada PIB-presença, se baseou nos mesmos critérios de formação da carteira PIB-negociabilidade. No entanto, aqui foram selecionadas as empresas com maior nível de presença nos pregões da $[\mathrm{B}]^{3}$, dentro dos setores e no período estudado, conforme a Tabela 5.

Tabela 5:

Composição da carteira de mercado PIB-presença

\begin{tabular}{|c|c|c|c|}
\hline \multicolumn{2}{|c|}{ Classificação } & $\begin{array}{l}\text { no de } \\
\text { ativos }\end{array}$ & Composição da carteira \\
\hline \multicolumn{2}{|c|}{ Agropecuária } & 5 & BRFS3 / JBSS3 / MRFG3 / BEEF3 / SLCE3 \\
\hline \multirow{4}{*}{ 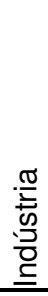 } & Ext. mineral & 4 & PETR4 / VALE3 / PETR3 / OGXP3 \\
\hline & Transformação & 11 & $\begin{array}{l}\text { GGBR4 /ABEV3 / USIM5 / CSNA3 / GOAU4 / EMBR3 / CSAN3 / WEGE3 / } \\
\text { KLBN4 / MYPK3 / PMAM3 }\end{array}$ \\
\hline & Construção & 4 & CYRE3 / MRVE3 / EVEN3 / EZTC3 \\
\hline & Siup & 12 & $\begin{array}{l}\text { CCRO3 / CMIG4 / VIVT4 / BRKM5/ SBSP3 / ENBR3 / EQTL3 / CESP6 / } \\
\text { CPFE3 / CPLE6 / LIGT3 / TRPL4 }\end{array}$ \\
\hline \multirow{6}{*}{ 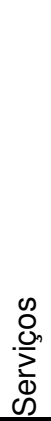 } & Comércio & 8 & LREN3 / LAME4 / PCAR4 / NATU3 / RENT3 / LAME3 / GRND3 / BTOW3 \\
\hline & Trans. arm. e correio & 3 & GOLL4 / POMO4 / TGMA3 \\
\hline & $\begin{array}{l}\text { Serviços de } \\
\text { informação } \\
\end{array}$ & 2 & TOTS3 / VLID3 \\
\hline & $\begin{array}{l}\text { Financeiras e } \\
\text { seguros }\end{array}$ & 9 & $\begin{array}{l}\text { ITUB3 / BBDC4 / BBAS3 / ITSA4 / BBDC3 / BRSR6 / SULA11 / PSSA3 / } \\
\text { ABCB3 }\end{array}$ \\
\hline & Outros & 3 & BRAP4 / OIBR4 / ODPV3 \\
\hline & $\begin{array}{l}\text { Imobiliários e } \\
\text { aluguéis }\end{array}$ & 7 & BRML3 / PDGR3 / GFSA3 / MULT3 / RSID3 / IGTA3 / TCSA3 \\
\hline
\end{tabular}

Fonte: Dados da pesquisa 


\subsection{Formação da carteira PIB-número}

Esta carteira tem como critério o número igual de empresas entre os setores. Dessa forma, esta carteira contempla 55 ativos, sendo 5 empresas por segmento do PIB conforme apresentadas na Tabela 6.

Tabela 6:

Composição da carteira de mercado PIB-número

\begin{tabular}{|c|c|c|c|}
\hline \multicolumn{2}{|c|}{ Classificação } & $\mathrm{n}$ - de ativos & Composição da carteira \\
\hline \multicolumn{2}{|c|}{ Agropecuária } & 5 & BRFS3 / JBSS3 / MRFG3 / BEEF3 / SLCE3 \\
\hline \multirow{4}{*}{ 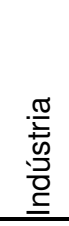 } & Ext. mineral & 5 & PETR4 / VALE3 / PETR3 / OGXP3 / MMXM3 \\
\hline & Transformação & 5 & GGBR4 /ABEV3 / USIM5 / CSNA3 / EMBR3 \\
\hline & Construção & 5 & CYRE3 / MRVE3 / EVEN3 / EZTC3 / HBOR3 \\
\hline & Siup & 5 & CCRO3 / CMIG4 / VIVT4 / BRKM5/ SBSP3 \\
\hline \multirow{6}{*}{ 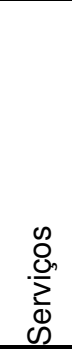 } & Comércio & 5 & LREN3 / LAME4 / PCAR4 / NATU3 / RENT3 \\
\hline & Trans. arm. e correio & 5 & GOLL4 / POMO4 / TGMA3 / KEPL3 / LOGN3 \\
\hline & Serviços de informação & 5 & TOTS3 / VLID3 / CARD3 / ESTC3 / CIEL3 \\
\hline & Financeiras e seguros & 5 & ITUB3 / BBDC4 / BBAS3 / ITSA4 / BBDC3 \\
\hline & Outros & 5 & BRAP4 / OIBR4 / ODPV3 / UNIP6 / BBRK3 \\
\hline & Imobiliários e aluguéis & 5 & BRML3 / PDGR3 / GFSA3 / MULT3 / RSID3 \\
\hline
\end{tabular}

\section{Resultados}

A Figura 3 apresenta a evolução do retorno ao longo do tempo das carteiras de mercado testadas neste trabalho. Pode-se observar um movimento semelhante entre os portfólios. No entanto é notável o movimento suave das carteiras de mercado baseadas na composição do PIB. Este comportamento dá-se em razão da diversificação de ativos. A alta concentração do índice lbovespa, motiva sua maior volatilidade.

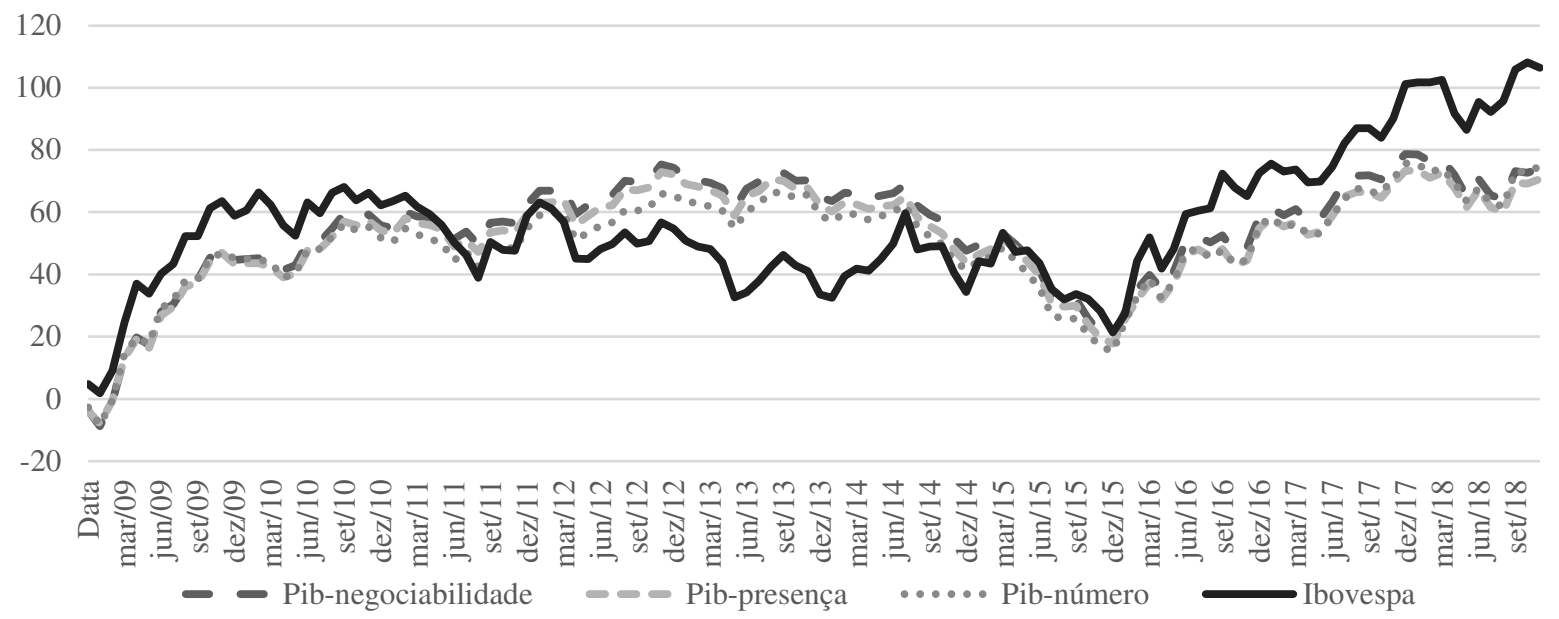

Figura 3:Retorno percentual ao longo do tempo das carteiras de mercado Fonte: Dados da pesquisa

Assim, de forma quantitativa observa-se na Tabela 7 a estatística descritiva das carteiras. Por meio da correlação dos portfólios, nota-se o trade-off entre risco e retorno das carteiras. Desta forma, pode-se observar a Teoria de Markowitz (1952) de forma direta.

Analisando em paralelo as carteiras Beta propostas para os testes. Denominadas assim devido suas seleções e formações ocorrerem de acordo com o tamanho dos betas de cada ativo. Sendo separados 70 ações em 10 grupos, em ordem decrescente de betas. 
Tabela 7:

Estatística descritiva das carteiras de mercado

\begin{tabular}{|c|c|c|c|c|c|c|c|c|c|c|c|}
\hline & $\bar{X}$ & $\sigma$ & $M$ & Min & Max & Assim & Curt. & $\rho$ PIB-negoc & $\rho$ PIB-pres & $\rho$ PIB-num & $\rho$ lbovespa \\
\hline PIB-negoc & 0.6175 & 43.509 & 0.2466 & -84.211 & 139.549 & 0.3628 & -0.1003 & 10.000 & 0.9963 & 0.9854 & 0.8339 \\
\hline PIB-pres & 0.5889 & 42.963 & 0.2189 & -89.626 & 136.958 & 0.3398 & -0.1248 & 0.9963 & 10.000 & 0.9851 & 0.8324 \\
\hline PIB-num & 0.6232 & 44.404 & -0.0462 & -90.502 & 149.397 & 0.4883 & 0.2672 & 0.9854 & 0.9851 & 10.000 & 0.8396 \\
\hline Ibovespa & 0.8864 & 59.957 & 0.5650 & -118.600 & 169.700 & 0.2485 & -0.3314 & 0.8339 & 0.8324 & 0.8396 & 10.000 \\
\hline
\end{tabular}

Fonte: Dados da pesquisa

Já por meio das Tabelas 8 e 9, pode-se notar a versatilidade das carteiras, demonstrada pela alta variabilidade de suas estatísticas descritivas e correlações. Com carteiras com desvios-padrão de 3,98 a 8,12, um range de retornos de 41,49 pontos percentuais e coeficientes de correlação decrescentes entre as carteiras. Tal matização gera grande número de possibilidades nos testes, criando assim proporcional quantidade e volubilidade de resultados. O que traz muitos benefícios para o estudo teórico, visto que torna o mesmo ainda mais próximo da aplicação real.

\section{Tabela 8:}

Estatística descritiva das carteiras beta

\begin{tabular}{|c|c|c|c|c|c|c|c|c|c|c|}
\hline & Beta 1 & Beta 2 & Beta 3 & Beta 4 & Beta 5 & Beta 6 & Beta 7 & Beta 8 & Beta 9 & Beta 10 \\
\hline $\bar{X}$ & 1.15 & 1.55 & 1.38 & 1.43 & 1.25 & 1.77 & 1.54 & 0.82 & 1.47 & 1.25 \\
\hline$\sigma$ & 8.08 & 8.12 & 6.73 & 6.79 & 6.31 & 5.94 & 5.03 & 5.07 & 4.94 & 3.98 \\
\hline$M$ & 0.90 & 1.13 & 1.45 & 1.40 & 1.64 & 2.01 & 1.22 & 0.28 & 1.04 & 0.75 \\
\hline Min & -14.33 & -14.53 & -13.04 & -14.88 & -14.45 & -12.27 & -10.58 & -12.47 & -11.54 & -8.19 \\
\hline Max & 24.09 & 26.61 & 17.08 & 21.70 & 16.54 & 16.66 & 14.57 & 17.94 & 17.78 & 11.32 \\
\hline Assim & 0.51 & 0.44 & -0.11 & 0.33 & 0.01 & 0.07 & 0.15 & 0.34 & 0.28 & 0.23 \\
\hline Curt. & 0.03 & 0.31 & -0.30 & 0.35 & -0.32 & -0.64 & -0.21 & 0.35 & 0.36 & 0.06 \\
\hline
\end{tabular}

Fonte: Dados da pesquisa

Tabela 9:

Matriz de correlação das carteiras beta

\begin{tabular}{l|llllllllll}
\hline \multicolumn{1}{c}{} & Beta 1 & Beta 2 & Beta 3 & Beta 4 & Beta 5 & Beta 6 & Beta 7 & Beta 8 & Beta 9 & Beta 10 \\
\hline Beta 1 & 1.0000 & 0.8287 & 0.8062 & 0.8030 & 0.7910 & 0.7147 & 0.7633 & 0.6455 & 0.4885 & 0.4370 \\
Beta 2 & 0.8287 & 1.0000 & 0.7816 & 0.7123 & 0.7559 & 0.6422 & 0.7416 & 0.6106 & 0.4750 & 0.4865 \\
Beta 3 & 0.8062 & 0.7816 & 1.0000 & 0.7076 & 0.8092 & 0.6510 & 0.7562 & 0.5860 & 0.5482 & 0.5715 \\
Beta 4 & 0.8030 & 0.7123 & 0.7076 & 1.0000 & 0.7262 & 0.7025 & 0.6984 & 0.6278 & 0.3963 & 0.4484 \\
Beta 5 & 0.7910 & 0.7559 & 0.8092 & 0.7262 & 1.0000 & 0.7195 & 0.8021 & 0.6269 & 0.6608 & 0.5420 \\
Beta 6 & 0.7147 & 0.6422 & 0.6510 & 0.7025 & 0.7195 & 1.0000 & 0.6501 & 0.6731 & 0.4534 & 0.5182 \\
Beta 7 & 0.7633 & 0.7416 & 0.7562 & 0.6984 & 0.8021 & 0.6501 & 1.0000 & 0.6053 & 0.5590 & 0.5714 \\
Beta 8 & 0.6455 & 0.6106 & 0.5860 & 0.6278 & 0.6269 & 0.6731 & 0.6053 & 1.0000 & 0.4345 & 0.4343 \\
Beta 9 & 0.4885 & 0.4750 & 0.5482 & 0.3963 & 0.6608 & 0.4534 & 0.5590 & 0.4345 & 1.0000 & 0.4393 \\
Beta 10 & 0.4370 & 0.4865 & 0.5715 & 0.4484 & 0.5420 & 0.5182 & 0.5714 & 0.4343 & 0.4393 & 1.0000 \\
\hline
\end{tabular}

Fonte: Dados da pesquisa

À vista disso, iniciando a análise das interações entre os portfólios apresentados, ou seja, as carteiras baseadas no PIB e as carteiras "betas". De acordo com a Tabela 10 têm-se os resultados mais relevantes para os estimadores, utilizando a carteira PIB-negociabilidade como proxy de carteira de mercado.

Como esperado, os melhores resultados são onde as carteiras tiveram os $p$-valores referentes a variável $\alpha$, maiores que o nível de significância de $5 \%(0,05)$, não rejeitando a hipótese nula mostrada na Equação 4. Então, pode-se observar na Tabela 11 que os melhores resultados se deram no curto prazo, com destaque para a janela de 07/2016 a 12/2018. Neste intervalo, somente a carteira $\beta_{6}$ exibiu um $p$-valor menor que 0,05 .

Uma notação relevante se dá quando observado o resultado no longo prazo, no hiato entre 01/2009 e 12/2018. Apenas as carteiras $\beta_{8}$ e $\beta_{10}$ obtiveram p-valor maior que o nível de significância estipulado. Assim, casos curiosos podem ser levantados, como as carteiras $\beta_{1}$ e $\beta_{4}$, que apenas rejeitaram $\mathrm{H}_{0}$ para o longo prazo. Um caso excepcional se deu com a carteira $\beta_{10}$, que não rejeitou a hipótese nula em nenhuma das 
janelas testadas. $O$ que pode dizer respeito a sua baixa correlação causal com a carteira PIB-negociabilidade. Como também a carteira $\beta_{8}$ que de 01/2014 a 06/2016, teve seu p-valor muito próximo a 0,05.

Tabela 10:

Resultado - PIB-negociabilidade como proxy de carteira de mercado

\begin{tabular}{|c|c|c|c|c|c|}
\hline \multirow{2}{*}{$\begin{array}{l}\text { Carteira de } \\
\text { ativo }\end{array}$} & \multicolumn{5}{|c|}{ Intercepto das retas de regressão } \\
\hline & $\begin{array}{l}01 / 2009 \text { - } \\
12 / 2018\end{array}$ & $\begin{array}{l}01 / 2009 \text { - } \\
06 / 2011\end{array}$ & $\begin{array}{l}07 / 2011 \text { - } \\
12 / 2013\end{array}$ & $\begin{array}{l}01 / 2014 \text { - } \\
06 / 2016\end{array}$ & $\begin{array}{l}07 / 2016 \text { - } \\
12 / 2018\end{array}$ \\
\hline Beta 1 & 0.6656 & 0.8691 & -0.1309 & 0.8407 & 10645 \\
\hline p-valor & 0.0335 & 0.1952 & 0.8062 & 0.2326 & 0.1386 \\
\hline Beta 2 & 10500 & 22601 & 0.1801 & -0.1963 & 0.5453 \\
\hline p-valor & 0.0079 & 0.0023 & 0.7701 & 0.8568 & 0.4051 \\
\hline Beta 3 & 0.8416 & 0.4663 & 0.9895 & 18179 & 0.5186 \\
\hline p-valor & 0.0025 & 0.3801 & 0.0297 & 0.0109 & 0.4050 \\
\hline Beta 4 & 0.8630 & 0.9644 & 0.5162 & 14493 & 0.7548 \\
\hline p-valor & 0.0202 & 0.1626 & 0.3977 & 0.1688 & 0.3248 \\
\hline Beta 5 & 0.6748 & 0.4603 & 0.3834 & 18683 & 0.6993 \\
\hline p-valor & 0.0288 & 0.4132 & 0.5410 & 0.0044 & 0.2302 \\
\hline Beta 6 & 11653 & 0.1861 & 12116 & 0.6395 & 25894 \\
\hline p-valor & 0.0013 & 0.7888 & 0.0766 & 0.3882 & 0.0029 \\
\hline Beta 7 & 0.9118 & 15749 & 11770 & 0.9531 & 0.4210 \\
\hline p-valor & 0.0012 & 0.0173 & 0.0255 & 0.1133 & 0.4494 \\
\hline Beta 8 & 0.1714 & -0.0103 & 0.9262 & -13762 & 0.2614 \\
\hline p-valor & 0.5886 & 0.9872 & 0.1238 & 0.0489 & 0.6894 \\
\hline Beta 9 & 0.7828 & 0.7324 & 0.1524 & 23834 & 0.3453 \\
\hline p-valor & 0.0373 & 0.3682 & 0.8506 & 0.0120 & 0.4969 \\
\hline Beta 10 & 0.5372 & 0.6803 & 0.7969 & -0.3369 & 0.2639 \\
\hline $\mathrm{p}$-valor & 0.0712 & 0.2342 & 0.1705 & 0.6449 & 0.6479 \\
\hline
\end{tabular}

Fonte: Dados da pesquisa

Ainda segundo a Tabela 11, nota-se que a razão $\mathrm{J}_{0}$ apresentou todos os valores abaixo do nível de significância de 0,05. Assim, seria possível rejeitar a hipótese nula na forma multivariada. No entanto, os valores $\mathrm{J}_{1}, \mathrm{~J}_{2} \mathrm{e}_{3}$ ficaram acima do nível de significância, não podendo assim rejeitar a hipótese nula de que o intercepto seja igual a zero. Como as estatísticas $\mathrm{J}_{1}$ e $\mathrm{J}_{3}$ levam em conta o fato de a amostra ser finita, ressalta a chance de a carteira ser eficiente no curto prazo. Principalmente para $\mathrm{J}_{2}$ e $\mathrm{J}_{3}$, que estipulam a estatística teste para os modelos onde a restrição de $\alpha=0$ é aplicada, conforme Equação 4. Logo, todos os p-valores nos subperíodos foram maiores, ou bem próximos de 0,05 . Com exceção da estatística $J_{1}$ para a janela entre 01/2014 e 06/2016, que no teste individual foi o intervalo com mais interceptos rejeitados.

Tabela 11:

Razões J - PIB-negociabilidade como proxy de carteira de mercado

\begin{tabular}{l|lllll}
\hline$H_{0}: \alpha=0$ & $01 / 2009-12 / 2018$ & $01 / 2009-06 / 2011$ & $07 / 2011-12 / 2013$ & $01 / 2014-06 / 2016$ & $07 / 2016-12 / 2018$ \\
\hline$J 0$ & 422.347 & 186.093 & 331.565 & 851.983 & 189.341 \\
$p$-valor & 0.0000 & 0.0455 & 0.0003 & 0.0000 & 0.0411 \\
$J 1$ & 38.363 & 11.786 & 20.999 & 53.959 & 11.992 \\
$p$-valor & 0.0002 & 0.3624 & 0.0787 & 0.0008 & 0.3507 \\
$J 2$ & 157.155 & 62.879 & 96.989 & 175.297 & 63.747 \\
$p$-valor & 0.1081 & 0.7905 & 0.4673 & 0.0634 & 0.7829 \\
J3 & 147.987 & 48.208 & 74.358 & 134.395 & 48.873 \\
$p$-valor & 0.1396 & 0.9028 & 0.6838 & 0.2001 & 0.8986 \\
\hline
\end{tabular}

Fonte: Dados da pesquisa

Ademais, dado que os testes das razões J implicam em grande parte na aceitação de os excessos de retorno serem explicados apenas pelo risco sistemático de forma multivariada. Para o CAPM ser válido, a carteira de mercado deve também ser eficiente no sentido "média-variância". Assim, foram testadas as seguintes hipóteses: $\mathrm{H}_{0}: \mathrm{Z}_{\mathrm{m}}=0$ e $\mathrm{H}_{\mathrm{a}}: \mathrm{Z}_{\mathrm{m}}>0$. Desta forma, neste teste, a eficiência da carteira significa rejeitar 
a hipótese nula. Vale ressaltar que a hipótese de $\mathrm{Z}_{\mathrm{m}}<0$ também considera a carteira ineficiente. Dado que não é interessante para o investidor, uma carteira com retorno negativo.

Então, observa-se na Tabela 12, que em nenhum período se pode rejeitar a hipótese nula. Além disso, a razão de Sharpe se mostrou negativa em três dos cinco períodos testados (01/2019 a 12/2018, 07/2011 a 12/2013 e 01/2014 a 06/2016). Logo, a carteira não é eficiente no sentido "média-variância". Desse modo, mesmo considerando que o primeiro e o último subperíodos explicam os excessos de retorno dos ativos através do risco de mercado, não se pode considerá-los eficientes quanto a carteira de mercado.

Tabela 12:

Teste de eficiência "média-variância" da carteira PIB-negociabilidade

\begin{tabular}{l|lllll}
\hline $\mathrm{H}_{0}: \mu_{\mathrm{m}}=0$ & $01 / 2009-12 / 2018$ & $01 / 2009-06 / 2011$ & $07 / 2011-12 / 2013$ & $01 / 2014-06 / 2016$ & $07 / 2016-12 / 2018$ \\
\hline $\mathrm{SR}$ & -0.0461 & 0.2312 & -0.0713 & -0.4640 & 0.0801 \\
$\mathrm{p}$-valor & 0.5184 & 0.4094 & 0.5282 & 0.6769 & 0.4684 \\
\hline
\end{tabular}

Fonte: Dados da pesquisa

Partindo para a carteira de mercado PIB-presença. Por meio da Tabela 13, nota-se que a mesma apresentou eficiência semelhante ao portfólio PIB-negociabilidade. No entanto, com leve melhora. Aqui o período mais longo de 01/2009 a 12/2018, teve o a não rejeitado em apenas duas das carteiras testadas, sendo $\beta_{8}$ e $\beta_{10}$ novamente. Carteiras essas, que também não rejeitaram $\mathrm{H}_{0}$ em nenhum dos subperíodos analisados. Entretanto, vale ressaltar a carteira $\beta_{10}$ exibiu uma diminuição notável em seus $p$-valores. Tendo seu p-valor no período, muito próximo do nível de significância de 0,05 (5\%).

Pode ser observado também, que as carteiras $\beta_{1}, \beta_{4}$ e $\beta_{6}$ rejeitaram a hipótese nula apenas no longo prazo. Com destaque para a carteira $\beta_{6}$, que rejeitou $\mathrm{H}_{0}$ para a carteira PIB-negociabilidade.

Tabela 13:

Resultado - PIB-presença como proxy de carteira de mercado

\begin{tabular}{|c|c|c|c|c|c|}
\hline \multirow{2}{*}{$\begin{array}{l}\text { Carteira de } \\
\text { ativo }\end{array}$} & \multicolumn{5}{|c|}{ Intercepto das retas de regressão } \\
\hline & $\begin{array}{l}01 / 2009 \text { - } \\
12 / 2018\end{array}$ & $\begin{array}{l}01 / 2009 \text { - } \\
06 / 2011\end{array}$ & $\begin{array}{l}07 / 2011- \\
12 / 2013\end{array}$ & $\begin{array}{l}01 / 2014 \text { - } \\
06 / 2016\end{array}$ & $\begin{array}{l}07 / 2016 \text { - } \\
12 / 2018\end{array}$ \\
\hline Beta 1 & 0.7167 & 0.9590 & -0.1041 & 0.8875 & 10.334 \\
\hline$p$-valor & 0.0250 & 0.1581 & 0.8553 & 0.2272 & 0.1440 \\
\hline Beta 2 & 10.953 & 23.450 & 0.2117 & -0.2585 & 0.5185 \\
\hline p-valor & 0.0073 & 0.0015 & 0.7425 & 0.8189 & 0.4410 \\
\hline Beta 3 & 0.8843 & 0.5284 & 10.166 & 18.760 & 0.4959 \\
\hline p-valor & 0.0017 & 0.3163 & 0.0322 & 0.0100 & 0.4323 \\
\hline Beta 4 & 0.9044 & 10.198 & 0.5482 & 15.550 & 0.7351 \\
\hline p-valor & 0.0139 & 0.1373 & 0.3553 & 0.1338 & 0.3447 \\
\hline Beta 5 & 0.7138 & 0.5097 & 0.4032 & 18.981 & 0.6706 \\
\hline p-valor & 0.0205 & 0.3623 & 0.5196 & 0.0063 & 0.2346 \\
\hline Beta 6 & 11.986 & 0.2339 & 12.280 & 0.7192 & 25.786 \\
\hline p-valor & 0.0009 & 0.7322 & 0.0744 & 0.3226 & 0.0035 \\
\hline Beta 7 & 0.9439 & 15.951 & 11.971 & 10.387 & 0.3990 \\
\hline p-valor & 0.0006 & 0.0139 & 0.0234 & 0.0731 & 0.4596 \\
\hline Beta 8 & 0.1987 & 0.0248 & 0.9462 & -13.593 & 0.2480 \\
\hline p-valor & 0.5301 & 0.9682 & 0.1125 & 0.0530 & 0.7110 \\
\hline Beta 9 & 0.8035 & 0.7738 & 0.1682 & 24.247 & 0.3305 \\
\hline$p$-valor & 0.0323 & 0.3454 & 0.8342 & 0.0110 & 0.5136 \\
\hline Beta 10 & 0.5589 & 0.7037 & 0.8144 & -0.2502 & 0.2480 \\
\hline p-valor & 0.0557 & 0.2047 & 0.1561 & 0.7288 & 0.6609 \\
\hline
\end{tabular}

Fonte: Dados da pesquisa

De acordo com a Tabela 14 nota-se uma semelhança entre as carteiras de mercado PIB-presença e PIB-negociabilidade. Tendo repetidamente a estatística $\mathrm{J}_{0}$ rejeitando a hipótese nula para todas as janelas estudadas. Vale também destacar que nos testes $\mathrm{J}_{2}$ e $\mathrm{J}_{3}$, de caráter restritivo, $\mathrm{H}_{0}$ não foi rejeitado em nenhum período. Igualmente a carteira PIB-negociabilidade. 
Tabela 14:

Razões J - PIB-presença como proxy de carteira de mercado

\begin{tabular}{l|lllll}
$\mathrm{H}_{0}: \alpha=0$ & $01 / 2009-12 / 2018$ & $01 / 2009-06 / 2011$ & $07 / 2011-12 / 2013$ & $01 / 2014-06 / 2016$ & $07 / 2016-12 / 2018$ \\
\hline J0 & 473.179 & 235.401 & 340.292 & 811.711 & 178.529 \\
p-valor & 0.0000 & 0.0089 & 0.0002 & 0.0000 & 0.0575 \\
J1 & 42.980 & 14.909 & 21.552 & 51.408 & 11.307 \\
p-valor & 0.0000 & 0.2176 & 0.0719 & 0.0011 & 0.3907 \\
J2 & 173.233 & 75.467 & 98.777 & 170.661 & 60.836 \\
p-valor & 0.0675 & 0.6730 & 0.4513 & 0.0729 & 0.8082 \\
J3 & 163.128 & 57.858 & 75.729 & 130.840 & 46.641 \\
p-valor & 0.0910 & 0.8329 & 0.6705 & 0.2190 & 0.9125 \\
\hline
\end{tabular}

Fonte: Dados da pesquisa

Já na Tabela 15 os testes de eficiência "média-variância" se mostraram iguais a carteira anterior. Com os mesmos períodos com a razão de Sharpe negativa. Além de não rejeitar a hipótese nula em nenhum dos casos.

Tabela 15:

Teste de eficiência "média-variância" da carteira PIB-presença

\begin{tabular}{l|lllll}
$\mathrm{H}_{0}: \mu_{\mathrm{m}}=0$ & $01 / 2009-12 / 2018$ & $01 / 2009-06 / 2011$ & $07 / 2011-12 / 2013$ & $01 / 2014-06 / 2016$ & $07 / 2016-12 / 2018$ \\
\hline $\mathrm{SR}$ & -0.0533 & 0.2204 & -0.0776 & -0.4744 & 0.0838 \\
$\mathrm{p}$-valor & 0.5212 & 0.4135 & 0.5307 & 0.6806 & 0.4669 \\
\hline
\end{tabular}

Fonte: Dados da pesquisa

Quanto a terceira carteira, denominada PIB-número. De acordo com a Tabela 16 pode-se observar que a mesma denotou um número maior de rejeições de $\mathrm{H}_{0}$. O único a chegar mais próximo foi o período de 07/2016 - 12/2018. Porém, a carteira Beta 6 teve seu intercepto sendo significativo para o modelo. Novamente as carteiras $\beta_{8}$ e $\beta_{10}$ não rejeitaram a hipótese nula no longo prazo. E somente o portfólio $\beta_{10}$ correspondeu a restrição de $\alpha=0$ em todas as janelas estudadas.

Tabela 16:

Resultado - PIB-número como proxy de carteira de mercado

\begin{tabular}{|c|c|c|c|c|c|}
\hline \multirow[b]{2}{*}{$\begin{array}{l}\text { Carteira de } \\
\text { ativo }\end{array}$} & \multicolumn{5}{|c|}{ Intercepto das retas de regressão } \\
\hline & $\begin{array}{l}01 / 2009 \text { - } \\
12 / 2018\end{array}$ & $\begin{array}{l}01 / 2009- \\
06 / 2011\end{array}$ & $\begin{array}{l}07 / 2011 \text { - } \\
12 / 2013\end{array}$ & $\begin{array}{l}01 / 2014- \\
06 / 2016\end{array}$ & $\begin{array}{l}07 / 2016- \\
12 / 2018\end{array}$ \\
\hline Beta 1 & 0.6518 & 12.605 & -0.2094 & 0.5640 & 0.8627 \\
\hline p-valor & 0.0303 & 0.0480 & 0.6606 & 0.3865 & 0.2394 \\
\hline Beta 2 & 10.301 & 26.817 & 0.0940 & -0.4522 & 0.3349 \\
\hline p-valor & 0.0119 & 0.0004 & 0.8681 & 0.6811 & 0.6254 \\
\hline Beta 3 & 0.8240 & 0.7794 & 0.9158 & 14.649 & 0.3689 \\
\hline p-valor & 0.0052 & 0.1592 & 0.0340 & 0.0516 & 0.6052 \\
\hline Beta 4 & 0.8543 & 12.285 & 0.4529 & 12.788 & 0.5862 \\
\hline p-valor & 0.0180 & 0.0668 & 0.4508 & 0.1961 & 0.4409 \\
\hline Beta 5 & 0.6659 & 0.6857 & 0.3330 & 15.919 & 0.5125 \\
\hline $\mathrm{p}$-valor & 0.0255 & 0.1965 & 0.6004 & 0.0108 & 0.3569 \\
\hline Beta 6 & 11.601 & 0.4061 & 11.808 & 0.4145 & 24.663 \\
\hline p-valor & 0.0009 & 0.5116 & 0.0658 & 0.5768 & 0.0048 \\
\hline Beta 7 & 0.9025 & 17.385 & 11.241 & 0.7328 & 0.2892 \\
\hline$p$-valor & 0.0014 & 0.0082 & 0.0361 & 0.2268 & 0.5896 \\
\hline Beta 8 & 0.1556 & 0.2279 & 0.8784 & -15.760 & 0.1502 \\
\hline $\mathrm{p}$-valor & 0.6402 & 0.7270 & 0.1539 & 0.0300 & 0.8310 \\
\hline Beta 9 & 0.7751 & 0.8389 & 0.1156 & 21.944 & 0.2495 \\
\hline p-valor & 0.0402 & 0.2908 & 0.8882 & 0.0193 & 0.6324 \\
\hline Beta 10 & 0.5315 & 0.8648 & 0.7565 & -0.3711 & 0.1852 \\
\hline$p$-valor & 0.0746 & 0.1312 & 0.2065 & 0.6047 & 0.7382 \\
\hline
\end{tabular}

Fonte: Dados da pesquisa 
No entanto, nos testes multivariados (razões J) da Tabela 17, nota-se que no último subperíodo $\mathrm{H}_{0}$ não pode ser rejeitado. Neste hiato nenhum dos testes $\mathrm{J}$ rejeitam a hipótese nula. Ademais, as razões $\mathrm{J}_{2}$ e $\mathrm{J}_{3}$ (com restrição), foram eficientes em todas as janelas.

\section{Tabela 17:}

Razões J - PIB-número como proxy de carteira de mercado

\begin{tabular}{l|lllll}
\hline $\mathrm{H}_{0}: \alpha=0$ & $01 / 2009-12 / 2018$ & $01 / 2009-06 / 2011$ & $07 / 2011-12 / 2013$ & $01 / 2014-06 / 2016$ & $07 / 2016-12 / 2018$ \\
\hline J0 & 413.612 & 334.225 & 310.816 & 724.935 & 156.108 \\
p-valor & 0.0000 & 0.0002 & 0.0006 & 0.0000 & 0.1113 \\
J1 & 37.570 & 21.168 & 19.685 & 45.913 & 0.9887 \\
p-valor & 0.0002 & 0.0766 & 0.0979 & 0.0021 & 0.4850 \\
J2 & 154.341 & 97.537 & 92.637 & 160.073 & 54.584 \\
p-valor & 0.1170 & 0.4624 & 0.5073 & 0.0994 & 0.8585 \\
J3 & 145.338 & 74.778 & 71.021 & 122.722 & 41.848 \\
p-valor & 0.1500 & 0.6797 & 0.7158 & 0.2673 & 0.9386 \\
\hline
\end{tabular}

Fonte: Dados da pesquisa

Já os testes de eficiência em "média-variância" (Tabela 18), obtiveram os mesmos resultados das carteiras PIB-negociabilidade e PIB-presença. Mostrando a ineficiência da carteira PIB-número como carteira de mercado para o modelo CAPM.

\section{Tabela 18:}

Teste de eficiência "média-variância" da carteira PIB-número

\begin{tabular}{l|lllll}
\hline $\mathrm{H}_{0}: \mu_{\mathrm{m}}=0$ & $01 / 2009-12 / 2018$ & $01 / 2009-06 / 2011$ & $07 / 2011-12 / 2013$ & $01 / 2014-06 / 2016$ & $07 / 2016-12 / 2018$ \\
\hline $\mathrm{SR}$ & -0.0439 & 0.1802 & -0.0555 & -0.4216 & 0.1071 \\
$\mathrm{p}$-valor & 0.5175 & 0.4291 & 0.5219 & 0.6618 & 0.4577 \\
\hline
\end{tabular}

Fonte: Dados da pesquisa

Conforme demonstrado na Tabela 19, foram realizados os testes de eficiência tendo como proxy de carteira de mercado o índice bovespa, que é o portfólio mais utilizado em tal papel. Os ensaios foram realizados para efeito de comparação entre as carteiras propostas, podem assim observar se as mesmas se mostram mais eficientes que a carteira atualmente utilizada no cenário brasileiro. Nesse sentido, pode ser observado que existe uma eficiência individualizada no período de 07/2016 - 12/2018 e no período completo $01 / 2009$ - 12/2018. Nota-se também que o lbovespa, possui menos casos de rejeição que as carteiras antes testadas. No entanto, isso não é o suficiente para declarar sua eficiência.

Tabela 19:

lbovespa como proxy de carteira de mercado

\begin{tabular}{|c|c|c|c|c|c|}
\hline \multirow[b]{2}{*}{$\begin{array}{l}\text { Carteira de } \\
\text { ativo }\end{array}$} & \multicolumn{5}{|c|}{ Intercepto das retas de regressão } \\
\hline & $\begin{array}{l}01 / 2009 \text { - } \\
12 / 2018\end{array}$ & $\begin{array}{l}01 / 2009- \\
06 / 2011\end{array}$ & $\begin{array}{l}07 / 2011 \text { - } \\
12 / 2013\end{array}$ & $\begin{array}{l}01 / 2014 \text { - } \\
06 / 2016\end{array}$ & $\begin{array}{l}07 / 2016- \\
12 / 2018\end{array}$ \\
\hline Beta 1 & 0.2537 & 14.735 & 0.6603 & -18.269 & 0.2722 \\
\hline p-valor & 0.5662 & 0.1572 & 0.2978 & 0.0294 & 0.7943 \\
\hline Beta 2 & 0.6630 & 30.512 & 10.584 & -16.846 & -0.2767 \\
\hline p-valor & 0.1977 & 0.0198 & 0.1312 & 0.0748 & 0.7932 \\
\hline Beta 3 & 0.5037 & 0.9483 & 16.232 & -0.6616 & -0.2082 \\
\hline p-valor & 0.2009 & 0.2554 & 0.0119 & 0.4528 & 0.8083 \\
\hline Beta 4 & 0.5545 & 12.383 & 10.861 & -0.7327 & 0.0875 \\
\hline p-valor & 0.2011 & 0.0764 & 0.1220 & 0.5153 & 0.9273 \\
\hline Beta 5 & 0.3767 & 0.9410 & 0.7593 & -0.6228 & 0.0366 \\
\hline p-valor & 0.3589 & 0.2681 & 0.2817 & 0.4520 & 0.9680 \\
\hline Beta 6 & 0.9099 & 0.5461 & 17.446 & -11.085 & 21.571 \\
\hline$p$-valor & 0.0273 & 0.5080 & 0.0072 & 0.1793 & 0.0351 \\
\hline Beta 7 & 0.6838 & 17.570 & 16.632 & -0.7256 & -0.0557 \\
\hline$p$-valor & 0.0330 & 0.0099 & 0.0029 & 0.2561 & 0.9388 \\
\hline Beta 8 & -0.0334 & 0.3819 & 13.365 & -21.918 & -0.1095 \\
\hline p-valor & 0.9314 & 0.6420 & 0.0330 & 0.0020 & 0.9058 \\
\hline Beta 9 & 0.6290 & 10.569 & 0.2782 & 0.8735 & -0.1662 \\
\hline p-valor & 0.1227 & 0.2419 & 0.7416 & 0.3748 & 0.7425 \\
\hline Beta 10 & 0.4103 & 10.417 & 0.9526 & -0.8618 & 0.0572 \\
\hline p-valor & 0.2318 & 0.1631 & 0.1497 & 0.2238 & 0.9289 \\
\hline
\end{tabular}

Fonte: Dados da pesquisa 
As razões $\mathrm{J}$ (Tabela 20) explicam melhor o que foi visto nos testes individuais. Nota-se que o lbovespa apresenta menos rejeições a hipótese nula. Com destaque para os períodos de 01/2009 a 12/2018, de 01/2009 a 06/2011 e de 07/2016 a 12/2018, onde nenhum p-valor foi inferior ao nível de significância de 5\% $(0,05)$. Mostrando assim, um resultado contraditório entre os testes multivariados e os testes individuais no período de 10 anos. Pois, os testes unitários tiveram várias rejeições a $\mathrm{H}_{0}$. No entanto, conjuntamente essas rejeições não tiveram efeito, tão quanto no modelo restrito ou no modelo irrestrito.

\section{Tabela 20:}

Razões J - Ibovespa como proxy de carteira de mercado

\begin{tabular}{l|lllll}
\hline $\mathrm{H}_{0}: \alpha=0$ & $01 / 2009-12 / 2018$ & $01 / 2009-06 / 2011$ & $07 / 2011-12 / 2013$ & $01 / 2014-06 / 2016$ & $07 / 2016-12 / 2018$ \\
\hline J0 & 151.867 & 136.602 & 457.359 & 344.089 & 124.992 \\
p-valor & 0.1254 & 0.1891 & 0.0000 & 0.0002 & 0.2530 \\
J1 & 13.795 & 0.8651 & 28.966 & 21.792 & 0.7916 \\
p-valor & 0.1992 & 0.5784 & 0.0221 & 0.0691 & 0.6377 \\
J2 & 62.103 & 48.889 & 120.654 & 99.547 & 45.378 \\
p-valor & 0.7973 & 0.8985 & 0.2807 & 0.4445 & 0.9198 \\
J3 & 58.481 & 37.482 & 92.502 & 76.320 & 34.790 \\
p-valor & 0.8279 & 0.9580 & 0.5085 & 0.6647 & 0.9678 \\
\hline
\end{tabular}

Fonte: Dados da pesquisa

Dessa forma, de acordo com a Tabela 21, apesar de o índice Bovespa ser eficiente explicando os excessos dos retornos dos ativos em alguns períodos. Não pode ser observada sua eficiência quanto a "média-variância", demonstrando também razão de Sharpe negativa em duas ocasiões.

Tabela 21:

Teste de eficiência "média-variância" do lbovespa

\begin{tabular}{l|lllll}
\hline $\mathrm{H}_{0}: \mu_{\mathrm{m}}=0$ & $01 / 2009-12 / 2018$ & $01 / 2009-06 / 2011$ & $07 / 2011-12 / 2013$ & $01 / 2014-06 / 2016$ & $07 / 2016-12 / 2018$ \\
\hline $\mathrm{SR}$ & 0.0113 & 0.1816 & -0.2254 & -0.1069 & 0.2146 \\
$\mathrm{p}$-valor & 0.4955 & 0.4286 & 0.5884 & 0.5422 & 0.4158 \\
\hline
\end{tabular}

Fonte: Dados da pesquisa

Por fim, destaca-se ainda, que não tendo sua média estatisticamente diferente de zero, o retorno do Ibovespa apresenta resultados marginalmente superiores as demais carteiras testadas, visto que seu SR se mostrou superior a zero em um número maior de períodos.

\section{Conclusões}

O objetivo desta pesquisa foi testar a eficiência ex-ante das carteiras propostas através da composição do PIB (PIB-negociabilidade, PIB-presença e PIB-número), utilizados como proxies para a carteira de mercado no contexto do modelo CAPM, comparando-as com a eficiência do índice lbovespa para o mesmo fim. Assim, foram testadas as seguintes hipóteses: $\mathrm{H}_{1}$ : Uma carteira hipotética de mercado baseada na composição do PIB, formada por empresas de cada setor do mesmo, explica por si só o retorno de uma carteira de ativos, e $\mathrm{H}_{2}$ : Uma carteira hipotética de mercado baseada na composição do PIB, formada por empresas de cada setor do mesmo, é eficiente em "média-variância".

Os resultados mostraram que todas as carteiras propostas foram ineficientes no sentido 'médiavariância', não confirmando assim as hipóteses $\mathrm{H}_{1}$ e $\mathrm{H}_{2}$. Tais conclusões também foram identificadas nos estudos de Silva e Motta (2002), Araujo, Fajardo e Di Tavani (2006), Hagler e Brito (2007), Volpe (2010), assim como, Pereira e Laurini (2020), não obstante, as características do contexto brasileiro.

Contudo, alguns subperíodos mostraram boa resposta aos testes. Em principal, a janela entre 07/2016 e 12/2018, que não rejeitou as hipóteses testadas em $90 \%$ dos casos. Dando a entender que, assim como, os estudos a respeito da correlação entre PIB e Ibovespa, a janela de análise pode interferir nos resultados obtidos.

Utilizar a composição do Produto Interno Bruto para formar uma proxy de carteira de mercado para o modelo CAPM, se destaca, posto que a variável macroeconômica abrange toda a produção da economia brasileira. Isso explica a utilização da variável por Araujo, Fajardo e Di Tavani (2006). Porém, mesmo o índice lbovespa apresentando um resultado marginal maior que os demais, não se pode afirmar que o mesmo, é uma proxy de carteira de mercado para o modelo CAPM, visto que este índice não cumpre as premissas de eficiência para a versão Sharpe-Lintner. Apesar disso, o índice se mostra como possível alternativa, para sua aplicação prática no mundo real. 
Também foi possível concluir que apesar da utilização de dados em um período de 10 anos com relativa estabilidade na economia brasileira, a metodologia discutida por Campbell, Lo e MacKinlay (1997), não foi possível confirmar às premissas levantadas nas hipóteses para o cenário nacional, de acordo com as carteiras propostas neste estudo. Assim, pesquisas futuras poderiam ser mais precisas, ao testarem às subdivisões dentro de cada proxy adotadas nesse estudo, como as premissas de carteira eficiente para às subdivisões em negociabilidade, presença, número e no índice lbovespa, porém fazendo um recorte antes e após a Covid-19, pois tal efeito da pandemia pode interferir na estabilidade da economia brasileira. Pode também ser adicionada uma comparação com modelos como os de Guermat (2014) e Pereira e Laurini (2020), o que poderá refletir em resultados diferentes dos apresentados neste estudo.

\section{Referências}

Araújo, E., Fajardo, J., \& Di Tavani, L. C. (2006). CAPM usando uma carteira sintética do PIB Brasileiro. Estudos Econômicos, São Paulo, SP, Brasil, 36(3), 465-505. https://doi.org/10.1590/S0101-41612006000300003

Asprem, M. (1989). Stock prices, asset portfolios and macroeconomic variables in ten European countries. Journal of Banking \& Finance, 13, 589-612. https://doi.org/10.1016/0378-4266(89)90032-0

Barro, R. J. (1990). The stock market and investment. The Review of Financial Studies, 3(1), 115-131. https://doi.org/10.1093/rfs/3.1.115

Bernardelli, L. V., \& Bernardelli, A. G. (2016). Análise sobre a Relação do Mercado Acionário com as Variáveis Macroeconômicas no Period de 2004 a 2014. Revista Evidenciação Contábil \& Finanças, 4(1), 417, https://doi.org/10.18405/recfin20160101

Bernardelli, L. V., \& De Castro, G. H. L. (2020). Mercado acionário e variáveis macroeconômicas: evidências para o Brasil. Revista Catarinense da Ciência Contábil, 19, 2892. https://doi.org/10.16930/2237$\underline{766220202892}$

Black, F. (1972). Capital Market Equilibrium with Restricted Borrowing. The Journal of Business, 45(3), 444455. https://doi.org/10.1086/295472

Campbell, J. Y., Lo, A., \& MacKinlay, C. (1997). The Econometrics of Financial Markets Princeton University Press Princeton. New Jersey: MacKinlay, 2. https://doi.org/10.1515/9781400830213

Carvalho, P. L., \& Sekunda, A. (2020). Influência de variáveis macroeconômicas sobre o desempenho do mercado de capitais brasileiro. Anais do XX USP Internacional Conference in Accounting, São Paulo, SP, Brasil.

Dufour, J.M., \& Tessier, D. (2006). Short-run and long-run causality between monetary policy variables and stock prices (No. 2006-39). Bank of Canada.

Fama, E. F. (1981). Stock returns, real activity, inflation, and money. The American Economic Review, 71(4), 545-565.

Fama, E. F. (1990). Stock returns, expected returns, and real activity. The Journal of Finance, 45(4), 10891108. https://doi.org/10.1111/j.1540-6261.1990.tb02428.x

Fama, E. F., \& French, K. R. (2007). O modelo de precificação de ativos de capital: teoria e evidências. Revista de Administração de Empresas, 47(2), 103-118. https://doi.org/10.1590/S0034$\underline{75902007000200015}$

Gan, C., Lee, M., Yong, H. H. A., \& Zhang, J. (2006). Macroeconomic variables and stock market interactions: New Zealand evidence. Investment Management and Financial Innovations, 3(4), 89-101.

Gibbons, M. R., Ross, S. A., \& Shanken, J. (1989). A Test of the Efficiency of a Given Portfolio. Econometrica, 57(5), 1121-1152. https://doi.org/10.2307/1913625

Grôppo, G. S. (2004). Causalidade das variáveis macroeconômicas sobre o lbovespa. Dissertação de Mestrado, Universidade de São Paulo, São Paulo, Brasil. https://doi.org/

https://doi.org/10.11606/D.11.2004.tde-06012005-165535 
Guermat, C. (2014). Yes, the CAPM is testable. Journal of Banking \& Finance, 46, 31-42.

https://doi.org/10.1016/j.jbankfin.2014.05.001

Hagler, C. E. M., \& Brito, R. D. De O. (2007). Sobre a eficiência dos índices de ações brasileiros. Revista de Administração, 42(1), 74-85. https://doi.org/10.1590/S1415-65552001000300011

Harry M. (1952). Portfolio Selection Harry Markowitz. The Journal of Finance, 7(1), 77-91. https://doi.org/10.1111/j.1540-6261.1952.tb01525

Hou, Y. (2002). Testing the CAPM by a synthetic return on GDP as the market return. Economics Department, Yale University, Connecticut, Estados Unidos da América, 3-53.

Jobson, J. D., Korkie, Bob. (1982). Potential performance and tests of portfolio efficiency. Journal of Financial Economics, 10(4), 433-466. https://doi.org/10.1016/0304-405X(82)90019-8

Kan, R., Robotti, C., Shanken, J. (2013). Pricing model performance and the two-pass cross-sectional regression methodology. The Journal of Finance, 68(6), 2617-2649. https://doi.org/10.1111/jofi.12035

Kandel, S., \& Stambaugh, R. F. (1995). Portfolio inefficiency and the cross-section of expected returns. The Journal of Finance, 50(1), 157-184, https://doi.org/10.1111/i.1540-6261.1995.tb05170.x

Kwon, C. S., \& Shin, T. S. (1999). Cointegration and causality between macroeconomic variables and stock market returns. Global Finance Journal, 10(1), 71-81. https://doi.org/10.1016/S1044-0283(99)00006-X

Lintner, J. (1965). Security Prices, Risk, and Maximal Gains From Diversification. The Journal of Finance, 20(4), 587-615. https://doi.org/10.1111/j.1540-6261.1965.tb02930

Machado, M. R. R., Gartner, I. R., De Souza Machado, L. (2017). Relação entre Ibovespa e Variáveis Macroeconômicas: Evidências a Partir de um Modelo Markov-Switching. Revista Brasileira de Finanças, 15(3), 435-468. https://doi.org/10.12660/rbfin.v15n3.2017.59406

Monteiro, B. R. L. G., Moraes, A. F., Dutra, T. C., \& Nascimento, J. P. (2013). Um estudo econométrico sobre as variávéis macroeconomicas e sua relação com o lbovespa no período julho de 1996 até Dezembro de 2013. Anais do XIII Simpósio de Excelência e Tecnologia, Minas Gerais, Brasil.

Nunes, M. S., Costa Jr, N. C. A., Meurer, R. (2005). A relação entre o mercado de ações e as variáveis macroeconômicas: uma análise econométrica para o Brasil. Revista Brasileira de Economia, 59(4), 585-607, https://doi.org/10.1590/S0034-71402005000400004

Nunes, M. S., Costa Jr, N. C. A., Seabra, F. (2003). Co-integração e causalidade entre variáveis macroeconômicas," risco Brasil" e retornos no mercado de ações brasileiro. Revista De Economia e Administração, 2(3), 26-42. https://doi.org/10.11132/rea.2002.44

Nunes, M., \& Silva, S. (2005). Política Monetária e Relação entre PIB Real e Mercado de Ações na Economia Brasileira [Monetary policy and the relationship between real GDP and stockmarket in the Brazilian economy], MPRA Paper 4158, University Library of Munich, Germany.

Pereira, M. V. L., Araújo, L. C., Iquiapaza, R. A. (2020). Cointegração e previsibilidade de abordagens VECM para o Ibovespa. Revista Brasileira de Financas, 18(2), 82-121.

https://doi.org/10.12660/rbfin.v18n2.2020.79162

Pereira, C. V., \& Laurini, M. (2020). Portfolio Efficiency Tests with Conditioning Information-Comparing GMM and GEL Estimators (No. 202014). SSRN. https://doi.org/10.2139/ssrn.3421775

Pilinkus, D. (2009). Stock market and macroeconomic variables: evidence from Lithuania. Economics and Management, 14, p. 884-891. Disponível em: https://etalpykla.lituanistikadb.|t/object/LT-LDB-

0001:J.04 2009 1367168422680/

Ribeiro, A. A. S., Leite, Á. R., \& Justo, W. R. (2016). Análise de cointegração e causalidade entre variáveis macroeconômicas e o índice Dow Jones sobre o lbovespa. Revista de Administração da Universidade Federal de Santa Maria, 9(1), 121-137. https://doi.org/10.5902/1983465911741

Roll, R. (1977). A critique of the asset pricing theory's tests Part I: On past and potential testability of the 
theory. Journal of Financial Economics, 4(2), 129-176. https://doi.org/10.1016/0304-405X(77)90009-5

Schwert, G. W. (1990). Stock returns and real activity: A century of evidence. The Journal of Finance, 45(4), 1237-1257. https://doi.org/10.1111/j.1540-6261.1990.tb02434.x

Shanken, J. (1985). Multivariate tests of the zero-beta CAPM. Journal of Financial Economics, 14, 327-348. https://doi.org/10.1016/0304-405X(85)90002-9

Silva, F. M., \& Coronel, D. A. (2012). Análise da Causalidade e Cointegração entre Variáveis macroeconômicas e o lbovespa. Revista de Administração FACES Journal, 2(3), 31-52.

Silva, F. F., \& Motta, L. F. J. (2002). Teste do CAPM zero-beta no mercado de capitais brasileiro. Revista de Economia e Administração, 1(4). https://doi.org/10.11132/rea.2002.28

Silva, Jr., J. C. A., Menezes, G., \& Fernandez, R. N. (2011). Uma análise VAR das relações entre o mercado de ações e as variáveis macroeconômicas para o Brasil. Economia e Desenvolvimento, 23. https://doi.org/10.5902/red.v0i23.4931

Omran, M. (2003). Time series analysis of the impact of real interest rates on stock market activity and liquidity in Egypt: Co-integration and error correction model approach. International Journal of Business, 8(3). https://doi.org/10.2139/ssrn.420248

Volpe, B. M. (2010). Qual índice de mercado utilizar? - Um teste das aproximações da carteira de mercado brasileira. Dissertação de mestrado, Fundação Getúlio Vargas Escola de Economia de São Paulo, São Paulo, Brasil.

William, S. (1964). Capital Asset Prices: A Theory of Market Equilibrium under Conditions of Risk. The Journal of Finance, 19(3), 1-19. https://doi.org/10.1111/j.1540-6261.1964.tb02865.x

\section{NOTAS}

\section{AGRADECIMENTOS}

Agradecemos ao Programa de Pós-Graduação em Ciências Contábeis da Universidade Federal do Espírito Santo - UFES pela acessibilidade dos dados coletados para a realização desta pesquisa.

\section{CONTRIBUIÇÃO DE AUTORIA}

Concepção e elaboração do manuscrito: A. S. Neto, V. F. Teixeira, D. Reina.

Coleta de dados: V. F. Teixeira, A. S. Neto

Análise de dados: V. F. Teixeira, A. S. Neto

Discussão dos resultados: V. F. Teixeira, A. S. Neto, D. Reina

Revisão e aprovação: V. F. Teixeira, D. Reina

\section{CONJUNTO DE DADOS DE PESQUISA}

O conjunto de dados que dá suporte aos resultados deste estudo não está disponível publicamente.

\section{FINANCIAMENTO}

Não se aplica.

\section{CONSENTIMENTO DE USO DE IMAGEM}

Não se aplica.

\section{APROVAÇÃO DE COMITÊ DE ÉTICA EM PESQUISA}

Não se aplica.

\section{CONFLITO DE INTERESSES}

Não se aplica.

\section{LICENÇA DE USO}

Os Direitos Autorais para artigos publicados neste periódico são do autor, com direitos de primeira publicação para a Revista. Em virtude de aparecerem nesta Revista de acesso público, os artigos são de uso gratuito, com atribuições próprias, em aplicações educacionais, de exercício profissional e para gestão pública. A Revista adotou a licença Creative Commons Atribuição 4.0 Internacional - CC BY NC ND. Esta licença permite acessar, baixar (download), copiar, imprimir, compartilhar, reutilizar e distribuir os artigos desde que com a citação da fonte, atribuindo os devidos créditos de autoria. Nesses casos, nenhuma permissão é necessária 
por parte dos autores ou dos editores. Autores têm autorização para assumir contratos adicionais separadamente, para distribuição não-exclusiva da versão do trabalho publicada nesta revista (ex.: publicar em repositório institucional ou um capítulo de livro).

\section{PUBLISHER}

Universidade Federal de Santa Catarina. Curso de Ciências Contábeis e Programa de Pós-graduação em Contabilidade. Publicação no Portal de Periódicos UFSC. As ideias expressadas neste artigo são de responsabilidade de seus autores, não representando, necessariamente, a opinião dos editores ou da universidade.

\section{EDITORES}

Carlos Eduardo Facin Lavarda e Suliani Rover

\section{HISTÓRICO}

Recebido em: 15/05/2020 - Revisado por pares em: 29/09/2020 - Reformulado em: 01/11/2020 Recomendado para publicação em: 21/01/2021 - Publicado em: 22/03/2021 